NBER WORKING PAPER SERIES

\title{
CONSPICUOUS CONSUMPTION AND RACE
}

\author{
Kerwin Kofi Charles \\ Erik Hurst \\ Nikolai Roussanov \\ Working Paper 13392 \\ http://www.nber.org/papers/w13392
NATIONAL BUREAU OF ECONOMIC RESEARCH
1050 Massachusetts Avenue
Cambridge, MA 02138
September 2007

We thank Mark Aguiar, Gary Becker, Matthew Gentzkow, Jonathan Guryan, Daniel Hamermesh, Kevin Murphy, Karl Scholz, Jesse Shapiro, and Francesco Trebbi for very useful comments and conversations. The paper has also benefited from comments from seminar participants at the University of Chicago, The IRP Summer Workshop, UCLA, Washington University, the University of Minnesota, Dartmouth College, the NBER Labor Studies Summer Program, the NBER Consumption Group Summer Program, and the St Louis Federal Reserve. We absolve all of responsibility for errors or omissions which remain. The views expressed herein are those of the author(s) and do not necessarily reflect the views of the National Bureau of Economic Research.

(C) 2007 by Kerwin Kofi Charles, Erik Hurst, and Nikolai Roussanov. All rights reserved. Short sections of text, not to exceed two paragraphs, may be quoted without explicit permission provided that full credit, including $\odot$ notice, is given to the source. 
Conspicuous Consumption and Race

Kerwin Kofi Charles, Erik Hurst, and Nikolai Roussanov

NBER Working Paper No. 13392

September 2007

JEL No. D12,D83,D91,J15

\begin{abstract}
$\underline{\text { ABSTRACT }}$
Using nationally representative data on consumption, we show that Blacks and Hispanics devote larger shares of their expenditure bundles to visible goods (clothing, jewelry, and cars) than do comparable Whites. We demonstrate that these differences exist among virtually all sub-populations, that they are relatively constant over time, and that they are economically large. While racial differences in utility preference parameters might account for a portion of these consumption differences, we emphasize instead a model of status seeking in which conspicuous consumption is used to reflect a household's economic position relative to a reference group. Using merged data on race and state level income, we demonstrate that a key prediction of our model -- that visible consumption should be declining in mean reference group income -- is strongly borne out in the data separately for each racial group. Moreover, we show that accounting for differences in reference group income characteristics explains most of the racial difference in visible consumption. We conclude with an assessment of the role of conspicuous consumption in explaining lower spending by racial minorities on items likes health and education, as well as their lower rates of wealth accumulation.

Kerwin Kofi Charles

Harris School of Public Policy

University of Chicago

1155 East 60th Street

Chicago, IL. 60637

and NBER

kcharles@uchicago.edu

Erik Hurst

Graduate School of Business

University of Chicago

Hyde Park Center

Chicago, IL 60637

and NBER

erik.hurst@gsb.uchicago.edu

Nikolai Roussanov

Department of Finance

The Wharton School

University of Pennsylvania

3620 Locust Walk

Philadelphia, PA 19104-6367

nroussan@wharton.upenn.edu
\end{abstract}




\section{Introduction}

In his famous study of consumption during the Gilded Age, Veblen (1899) speculated that, for the particular individuals he studied, "Consumption is evidence of wealth, and thus becomes honorific, and ...failure to consume a mark of demerit." This notion that an aim of consumption was to demonstrate one's economic position to observers Veblen dubbed “conspicuous consumption". Veblen's focus was on the very wealthy, but nothing in the main thrust of his argument requires that the phenomenon he identified apply to these households exclusively. ${ }^{1}$ In this paper, we study households' consumption of items which are readily observable in social interactions, and which are portable across interactions. We call these goods "visible consumption". Prompted by Veblen's insight that the consumption and display of these items communicates information about economic status, and by the fact that few easily observable variables are as strongly correlated with economic status as is an individual's race, we investigate a series of questions about visible consumption and race.

A large body of anecdotal evidence suggests that Blacks devote a larger share of their overall expenditure to consumption items that are readily visible to outside observers than do Whites. Automobiles, clothing, and jewelry are examples of these forms of "visible" consumption. There has to date, however, been little formal analysis by economists of the degree to which these racial differences in consumption patterns actually exist in the data, what accounts for them if they do, and what the consequences of any such differential expenditure might be. ${ }^{2,3}$ We address these questions in this paper.

The first part of our paper documents differences by race in expenditures devoted to visible consumption items. Using data from the Consumer Expenditure Survey (CEX) from the

\footnotetext{
${ }^{1}$ In fact, predating Veblen's analysis by a hundred and forty years, Adam Smith argued that the desire for rank, and the display of wealth associated with it, is nearly a universal feature of human behavior (Smith (1759)).

${ }^{2}$ One exception is an early piece by Alexis (1970) who examined racial differences in consumption patterns between 1935 and 1960 using data from The Consumer Purchases Survey: 1935-36 and early waves of the Federal Reserve's Survey of Consumer Finances. Similar to the findings we present below, Alexis found that Blacks were much more likely to spend on clothing (as a share of total expenditure) than similar Whites.

${ }^{3}$ Outside of economics, there is also limited work on the consumption patterns of Blacks. Examples include Mullins (1999), Lamont and Molnar (2001), and Chambers (2006).
} 
period of 1986-2002, we show that although, unconditionally, racial minorities and Whites spend approximately the same fraction of their resources on visible consumption, Blacks and Hispanics spend about thirty percent more on visible goods, after accounting for differences in permanent income. These expenditure differences are found within all sub-groups, except older households. We find that these racial gaps have been relatively constant over the past seventeen years. And, we show that spending on housing or differential treatment in the housing market cannot explain these patterns. Finally, the gaps are economically large: the absolute level annual dollar differential for visible consumption is on the order of $\$ 2300$, which is a non-trivial quantity given Black and Hispanic average income.

Because household spending must satisfy an inter-temporal budget constraint, spending devoted to visible consumption must be diverted from some alternative use. Reduced spending on specific types of current consumption on the one hand and lower savings (future consumption) on the other are the two possibilities. We show that the higher visible spending of racial minorities seems to come out of both future consumption and all other categories of current consumption: Blacks consume less than Whites in essentially every other expenditure category (aside from housing) to maintain higher visible consumption. ${ }^{4}$

What theoretical explanation accounts for these facts? One argument is that racial differences in expenditure on visible items derives simply from racial differences in preferences that minorities spend more on jewelry, cars and apparel because they like these items more than Whites. This argument is consistent with the basic facts, but it essentially tautological. Moreover, an argument centered on racial differences in preferences yields no prediction that is falsifiable in the data. An alternative explanation presumes that utility functions are the same across race, but that some external consideration makes people from different races place

\footnotetext{
${ }^{4}$ As discussed below, housing may be considered a visible good. In fact, we do find that Blacks and Hispanics spend more on housing than do comparable Whites. Our results (in terms of dollar magnitudes) get slightly stronger if we include housing as a component of visible consumption. But, given the large literature on racial differences in housing (which can explain the housing expenditure differences), we err on the side of caution by excluding housing from our base measure of visible goods.
} 
different marginal valuations on visible consumption items. Apart from the fact that it does not simply assume that Blacks behave differently from Whites because they have different preferences, an argument of this form yields additional predictions beyond the basic facts described above which should hold within a racial group, and which can also be empirically tested.

The alternative explanation we emphasize borrows from the extensive theoretical literature on the demand for social status. The key assumption of these models is that individuals care about how their income, consumption or wealth compares (or is thought to compare) to that of others in their reference group. In a signaling version of the status model, individuals' incomes or wealth is not observed but costly indicators of income, in the form of visible consumption, are. We show that under an intuitively appealing and simple formulation of a status function, visible consumption in such a model should be rising in own income, and decreasing in average reference group income.

Applying these insights, we argue that a status model of this form might predict racial differences in visible consumption even if Blacks, Whites, and Hispanics all have the same utility preference parameters. If otherwise identical racial minorities and Whites belong to communities with different average income, their incentives to consume visibility to satisfy a conspicuous status motive will be different. Interestingly, if the relative status model is correct, its predictions about the negative relationship between visible expenditure and higher reference group income should apply not only across races but among Whites who live in communities with lower average incomes.

To assess empirical support for the status argument, we combine data about expenditures from the CEX with income data from the Current Population Survey (CPS). Given the high levels of racial segregation in the data, we define an individual's reference group as being persons 
of the individual's race, living in his state. ${ }^{5}$ The basic idea is that visible consumption should be declining as the income of one's reference group goes up - holding constant their own income. Strikingly, we find that, consistent with the status argument, there is a strong negative association between visible spending and the mean income of one's reference group within all races. That is, separate analysis performed on a sample of White households finds the same thing as separate analyses done for racial minorities: increases in mean income of one's own race in the state are associated with reduced visible spending. As a falsification test of the status and reference group notion, we related household visible spending to mean incomes of other groups in the state and find either no effect or very modest positive effects. Additionally, we relate household nonvisible spending to reference average income and find no systematic relationship.

We then turn to the obvious next step: Do differences in reference group income explain the racial expenditure gaps that are our main focus? In a series of regressions, we show that accounting for the mean level of a household's reference group in the state explains most of the racial gap in visible spending. This conclusion is robust to a variety to sample modification and specification tests. Importantly, it is also robust to the addition of state fixed effects, which account for regional differences across all groups in the propensity to visibly consume.

In the last part of the paper, we discuss some potential implications of differential spending on conspicuous goods between the races. Holding lifetime resources constant, an increased propensity to spend on visible goods must necessarily mean lower consumption on other goods. We show that the Black-White gaps in education and health care spending (conditional on permanent income and other demographics) decline by 25 and 8 percentage points, respectively, after controlling for the share of spending allocated to visible goods. Given that the racial gap in visible spending falls with age, there is reason to believe that wealth accumulation could be affected by spending on visible goods. To this end, we show that wealth

\footnotetext{
${ }^{5}$ As we discuss below, state is the lowest level of location available in the CEX and thus is the finest spatial level at which we can test for the importance of reference group income.
} 
gap between Blacks and Whites, conditional on permanent income, declines by 50 percent after controlling for visible spending. Importantly, the decompositions in this final portion of the paper are not contingent on any particular theoretical account of why conspicuous consumption differences arise. Irrespective of why Blacks spend more on visible goods than comparable Whites there will be implications for other well-studied "racial gaps" in economic outcomes.

On the whole, the paper's results point to an important role for consumption items, apart from their direct consumption value. Although this exhibitionistic component has been long talked about in economics, we are aware of very little formal evidence brought to bear on the question, especially in terms of the racial differences that are our focus. ${ }^{6}$ Over the last decade, economists and sociologists have provided considerable empirical support for the notion that individuals care about their relative position in their community, often using evidence about subjective well being. ${ }^{7}$ Our work complements this literature in that we are able to link consumption patterns to social concerns by analyzing economic behavior directly. Perhaps more importantly, our specific focus on racial differences in consumption, and our results about the potential role played by the use and display of visible items, suggests that a deeper understanding of the racial gaps in wealth, savings and consumption that have long bedeviled economists and others will require further exploration of the issues raised in this paper.

\section{Data}

To examine racial differences in consumption patterns, we use data from the 1986-2002 CEX, collected by the United States Department of Labor. The CEX is an on-going rotating panel dataset, in which participating households are interviewed up to five times at three month intervals. In any given calendar quarter there are approximately 5,000 households in the survey, with some households entering the survey and others exiting the survey. The initial interview

\footnotetext{
${ }^{6}$ Notable recent exceptions include Ravina (2005) and Kapteyn et al (2006).

7 Recent examples include Luttmer (2005), Clark and Oswald (1996), McBride (2001) and Dynan and Ravina (2007). See also survey by Kahneman and Krueger (2006) and cites within.
} 
collects household demographic information, which is updated during subsequent interviews to reflect any changes in household composition. Information on annual income (during the previous twelve months) is collected during the second and fifth interviews. Additionally, the second through fifth interviews each collects detailed household expenditure information for the three calendar months immediately preceding the interview. The detailed expenditure information can be aggregated up to a broader set of consumption categories for the household.

Like previous users of CEX data, we aggregate to the consumption categories proposed by Sabelhaus and Harris (2000). We use the CEX family level extracts made available from the National Bureau of Economic Research (NBER). The Data Appendix discusses in detail the NBER CEX family extracts, the details of our sample selection criteria, and the 47 specific expenditure categories included in the Sabelhaus and Harris consumption classification. Appendix Table A1 lists the 15 broad consumption categories we explore in this paper and how they relate to the 47 categories in summarized in the Sabelhaus and Harris files. All data are deflated to 2005 dollars using the June CPI-U.

To summarize the sample selection criteria described in the Data Appendix, our primary analysis sample consists of Blacks, Whites, and Hispanics households, with heads between 18 and 49 years old. In some specifications, we explore the robustness of our results by examining the consumption patterns of older households and the sensitivity of our results to excluding younger households. Also, below, we look at the spending patterns of Asians, but because of small sample sizes Asians are not part of the main analysis sample.

To mitigate the effects of measurement error in the expenditure categories, the unit of analysis is the average quarterly expenditure within a consumption category over the period that the household is in the sample. In total, our primary analysis sample includes 48,758 households, comprised of 36,706 White households, 6,760 Black households, and 5,292 Hispanic households.

Descriptive statistics for the sample by race are shown in Table 1. There are two noteworthy things in Table 1. First, 27 percent of the sample has missing total family annual 
income where total annual income is defined to include labor, asset and transfer income. Over a similarly defined sample, less than one percent of households in the March Current Population Survey (CPS) (which is designed to measure labor market outcomes) have zero or negative reported annual total family income. It is well documented that the CEX has many more missing income observations compared to surveys designed to measure income like the CPS. The second noteworthy point in the table is that among those reporting positive income, White households have sixty-seven percent higher total income than Black households and sixty-one percent more than Hispanic households. The comparable numbers from the CPS are fifty-one and thirty-seven percent, respectively. The racial total expenditure differences from the CEX, however, line up nearly exactly with the income numbers from the CPS. Specifically, as seen in Table 1, Whites consume fifty percent more and thirty-eight percent more than Blacks and Hispanics, respectively. ${ }^{8}$

Our focus in the paper is on visible consumption expenditures - items for which expenditure is readily observable and which are highly portable, so that they are observed across a variety of interactions. Also, we want to identify goods with the characteristic that individual who consumer more of such goods are believed to be of better economic circumstances, on average, than individuals who consumers less of such goods. Simple introspection suggests what these items are likely to be, but rather than simply asserting what those items are, we conducted a simple survey designed to assess people's views about what expenditures are visible. ${ }^{9}$

\footnotetext{
${ }^{8}$ As discussed below, concern about the quality of current income data in the CEX is mitigated by our use of total expenditure as a permanent income proxy.

9 We are not the first to assess the visibility of different consumption goods using a survey. Heffetz (2007) sampled 480 individuals and asked them how long it would take them to observe whether an individual consumes an above average amount of particular consumption goods. Our survey was very much inspired by Heffetz work, but we conducted our own survey for three main reasons. First, given our focus on interactions with relatively unfamiliar individuals, we were more interested in the familiarity an individual needs to determine someone's above average consumption rather than the length of time it would take him to observe this. Second, we needed to ask individuals about the perceived income gradient associated with higher amounts of consumption for particular categories. In other words, is above average spending on a particular good a signal of higher income or wealth. Finally, Heffetz's survey, like ours, included a relatively small number of respondents and we were unsure if the results would extend to a broader population. It is encouraging, however, that our classification of visible goods is very similar to the classification proposed by Heffetz.
} 
We surveyed over 320 graduate students in the University of Chicago's Harris School of Public Policy and the University of Chicago's Graduate School of Business via an anonymous online survey. 213 students responded to the survey. The survey consisted of three parts. The first part asked about background information including age, sex, race and marital status. In the second part, respondents were asked the following question (Q2): "Consider a person who lives in a household and community roughly similar to yours. How closely would you have to interact with this person in order to observe that they consistently spend more than average on each of the following categories?" Their answers ranged from 1 (indicating that higher than average spending could be observed if the respondent did not interact socially with the person at all) to 5 (indicating that spending would never be observed). Appendix Table A2 details the survey questions and potential responses. The consumption categories asked of survey respondents were designed to approximate the CEX consumption categories outlined in Appendix Table A1.

In Q3 of the survey, we asked respondents the following: "Consider a randomly chosen individual in society. Imagine that this person's lifetime income suddenly increased by $20 \%$. For each item below, tell us how you would expect the person's spending on each of the following items to change". The answers again ranged from 1 to 5 with 1 being spending would fall, 2 being spending would stay the same, and 3-5 being spending increased by less than, exactly, or more than $20 \%$, respectively. The consumption categories for which this question was asked were the same as those in Q2.

Appendix Table A3 presents the survey results. The first column shows the proportion of survey respondents who thought they would be able to observe above-average spending on an item even if relatively unfamiliar with the consumer (responses "1" or " 2 " to Q2). We call these goods visible. The statistic in column 2 is the proportion of survey respondents who reported that the consumption item has at least an income elasticity of at least 1.

Respondents thought that the type of spending they would most readily observe is that on clothing, jewelry and vehicles (excluding maintenance). For example, nearly two-thirds of 
respondents reported that they would be able to ascertain above average spending on clothing and jewelry for individuals they hardly know. Other spending thought to be highly observable includes (in decreasing order) expenditures on tobacco products, shelter expenditures, alcohol and personal care expenditures. Spending on all other goods was thought to be hard to observe compared to these seven goods. The second column shows that only five items were thought to be both highly observable and also thought to have income elasticities greater than 1 . On one hand, an item like entertainment durables, which includes such things as televisions, was thought to have a high income elasticity but not to be especially observable. On the other hand, tobacco and alcohol spending are thought to be easily observable but have quite low expected income elasticities. Consistent with this survey evidence, in the cross-section CEX data, the combined alcohol/tobacco category was the only consumption category with a negative cross sectional income elasticity.

As will be made clear below, we wish to treat as "visible" goods which are easily observable and which have the characteristic that higher consumption of the good is generally associated with higher income. Given the results of the survey (and consistent with commonsense), we define visible consumption in our analysis as consisting of expenditures on apparel (including accessories such as jewelry), expenditures on personal care, and outlays on vehicles excluding maintenance.

One especially important item is housing. The survey evidence suggests that housing is both reasonably observable and that it has a high expected income elasticity. Our concern is that racial differences in housing expenditure might derive from differential treatment in the housing market - a phenomenon that has been the focus of a large literature. ${ }^{10}$ Differential treatment in the housing market could, by itself, cause minorities to have very different housing expenditures

\footnotetext{
${ }^{10}$ There is evidence that minorities face significantly higher rejection rates for mortgages which serves to limit their access to owner occupied housing (see Munnell et al. (1996) and Charles and Hurst (2002)). Moral hazard considerations cause rental prices to exceed the flow cost from owning an otherwise identical unit, so households who rent will pay more for housing services, all else equal, than those who own.
} 
than Whites, even if there were no conspicuous or exhibitionistic consideration informed housing expenditure. Previewing our later results, we find that minorities spend more for a unit of housing than do Whites, implying that if housing were lumped together with other visible spending, the overall difference in visible expenditure we estimate would be slightly larger. However, given the concerns about differential treatment in this particular market, we adopt the conservative policy of excluding housing from the measure of total spending in most of our main results. For the most part, we always treat housing separately, except for some robustness specifications in which we assess how the results are affected when housing expenditure is lumped in with overall visible spending.

Appendix Tables A4 summarizes expenditures in our CEX sample on visible and other goods. Overall, visible consumption expenditures comprise roughly 12 percent of household total expenditures, while spending on food and shelter represent roughly 20 percent and 25 percent, respectively, of total expenditures. The table shows that some CEX households spend nothing on some expenditure categories over their time in the survey. Thus, whereas nearly all households spend on food, housing, entertainment services, and visible goods, $57 \%$ of households spent nothing on education, and around $20 \%$ spent nothing on alcohol and tobacco. ${ }^{11}$

\section{Racial Differences in Conspicuous Consumption}

To document the basic facts about consumption patterns by race in the CEX, we estimate the following specification on a pooled sample of Black, White, and Hispanic household heads:

$$
\ln \left(\text { visible }_{i}\right)=\beta_{0}+\beta_{1} \text { Black }_{i}+\beta_{2} \text { Hispanic }_{i}+\gamma \text { Income }_{i}+\varphi \text { Expenditure }_{i}+\theta X_{i}+\eta_{i}
$$

where Black $_{i}$ is a dummy variable if household head $i$ is Black, Hispanic $c_{i}$ is a dummy variable if household head $i$ is Hispanic, and Income $_{i}$ is a vector of income controls for household $i$ including the log of total family income, a cubic in the level of total family income, and a dummy variable equal to one if total family income is zero or missing. Total family income includes the sum of

\footnotetext{
${ }^{11}$ In later analysis, we use Tobit analysis to deal with the large prevalence of zeros in particular consumption categories.
} 
all labor and non-labor income earned by all members of the household. We set the log of total family income equal to zero if total family income was zero. Expenditure $_{i}$ is a vector of total expenditure variables for household $i$ including the log of total expenditures and a cubic in the level of total expenditure. We include expenditure controls to proxy for the household's permanent income. According to the permanent income hypothesis, the level of current consumption should depend on lifetime (permanent) income and not simply current income. In essence, we are using total expenditures as our control for permanent income. ${ }^{12}$ Alternatively, by controlling for total expenditure, we are estimating the share of expenditure allocated to visible goods among people who spend the same amount in total. This approach yields exactly the estimate we want since we are interested in explaining how expenditures are allocated across consumption categories rather than the level of total expenditures.

$X_{i}$ is a vector of demographic controls including a quadratic in age, education controls, household wealth controls, year effects and indicator variables for the number of adults in the household, the number of total family members in the household, marital status, whether the household head is male, urbanicity, MSA residence, and Census region. ${ }^{13}$

Only 1 percent of the sample reports having no expenditures on visible goods over their time in the survey. Given the small occurrence of zeros in visible expenditures in our sample, it makes no difference if we estimate (1) via OLS setting the log visible expenditures to zero for those with zero visible expenditure or via a Tobit estimator which explicitly accounts for the censoring at zero. Table 2 presents the OLS estimates of (1).

If (1) is estimated including only the race dummies and excluding all of the other controls, Blacks and Hispanics are found to spend less on visible items than comparable Whites

\footnotetext{
12 Implicit in this identification is that the mapping of permanent income to total expenditures is constant across races. However, a large literature suggests that Blacks save less out of permanent income than do similar Whites (e.g., Hurst, Luoh and Stafford 1998). If Blacks do save less than comparable Whites, the estimated Black effect in (1) is downwards biased, making the estimate a lower bound on the racial difference in visible consumption.

13 For household wealth, we use the log of liquid assets if liquid assets are positive and a dummy for whether the household has positive liquid assets as controls. Liquid assets are defined as checking, saving, stock, and bond holdings.
} 
by 38 and 24 percent, respectively (Row 1 of Table 2). This is not surprising, since spending on visible goods increases with income as we show below, and since Blacks and Hispanics have much lower incomes than Whites. As expected, Row 2 shows that including the CEX controls for current income lowers both of the estimated minority race effects. However, as discussed above, current income is measured very poorly in the CEX. Moreover, consumption theory predicts that consumption decisions are based on permanent rather than current income. Row 3 shows that when both controls for current income and total expenditure (which proxies for permanent income) are added to the regression, the estimated effects indicate that Black and Hispanics consume 29 percent and 25 percent more visible goods than Whites with similar permanent income. The estimates in the fourth row show that it is the permanent income controls that drive the entire change in coefficient between the specifications in first and third rows. Excluding the current income controls from specification 3 leaves the racial dummies essentially unchanged.

Row 5-7 of the table show that including a full set of demographic controls does little to change the racial difference in visible consumption patterns after controlling for income and expenditure. ${ }^{14}$ For example, adding education controls in Row 5 leaves the race effects essentially unchanged. With the full set of demographic controls in Row 7, the estimated racial effects increase only slightly relative to the results with just the income and expenditure controls. In summary, Blacks and Hispanics consume 32 percent and 31 percent more visible goods, respectively, than comparable Whites. ${ }^{15}$

The racial difference in visible expenditures is large in absolute dollars. Appendix Table A4 shows that, on average, Whites spend about $\$ 7,204$ on visible items per year. The finding that Blacks and Hispanics spend 32 percent more than comparable Whites on visible goods therefore implies that Blacks and Hispanics spend on average roughly $\$ 2,300$ per year more on

\footnotetext{
14 The results are nearly identical if instead of pooling Whites, Blacks and Hispanics together we estimate the Black coefficient on a sample of only Whites and Blacks, and the Hispanic coefficient in a sample of only includes Whites and Hispanics.

15 The coefficients on the Black and Hispanic dummies from a median regression (otherwise analogous to the specification shown in row 7 of Table 2) were 0.36 and 0.38 respectively.
} 
visible goods than their White counterparts. This estimate is likely a lower bound given that the CEX has been found to under report total household consumption relative to data from the National Income and Product Accounts. To put these magnitudes in perspective, data from the March CPS shows that, for the 1990-2002 period, Black and Hispanic households had average incomes, respectively, of $\$ 42,500$ and $\$ 48,300$ in 2005 dollars. Outlays on visible goods thus represent a substantial fraction of the overall budget of minorities. ${ }^{16}$

Although to conserve space we do not report them in Table 2, we find some interesting patterns between individual level demographics and visible spending, net of the effect of current and permanent income. We find, first, that the propensity to purchase visible goods declines sharply with age. For example, relative to households with heads between 18 and 30 years old, households with heads between 26 and 29 are twenty-three percent less likely to spend on visible goods. The comparable coefficients on the age dummies for 30-33 year olds, 34-37 year olds, 3841 year olds, 42 to 45 year olds, and 46-49 year olds are, respectively, -37 percent, -44 percent, 55 percent, -56 percent and -62 percent. Second, we find that female-headed households are 15 percent more likely to spend on visible goods than their male headed counterparts. Lastly, the college educated, spend about 13 percent less on visible expenditures than their high school educated counterparts.

Figure 1 plots the visible expenditure Engel curves for Black and White households. To estimate these equations we regress, separately for Blacks and Whites, the log of visible expenditures on the log of current household income, instrumenting current household income with the total expenditure controls discussed above. This regression relates the log of visible expenditure to the portion of current income that is systematically related to total expenditure -

\footnotetext{
${ }^{16}$ We present results for Blacks, Hispanics, and Whites. We also explored but do not present because of sample size concerns differences in spending patterns between Asians and Whites. Asians, on average, spend 9 percent less on visible goods than Whites with similar permanent income and demographics.
} 
what theory suggests is permanent income. ${ }^{17}$ The figure shows that, for both Blacks and Whites, visible expenditures are luxury goods. The coefficient on log income in the IV regressions for Blacks and Whites, respectively, were 1.4 and 1.6. Second, Blacks, at every level of permanent income, spend more on visible goods then their White counterparts, with a $30 \%$ difference at the median income for the sample. ${ }^{18}$ Third, notice that the two Engle curves are essentially parallel, mitigating concerns that the main results derive in some way from a fundamental difference in the shapes of these relationships across race.

The finding that racial minorities exhibit a greater propensity to consume visible goods is robust to a variety of alternative specifications and restrictions, including restricting the sample to households with positive current income, excluding households with less than $\$ 23,200$ a year in total expenditures (which was the $25^{\text {th }}$ percentile of the expenditure distribution), excluding households under the age of 24 , including log expenditures on housing shelter as an additional control, restricting the sample to include only those who completed all four CEX surveys, including occupation dummies, and including city size controls. The results of these alternative specifications are shown in Appendix Table A5.

Table 3 reports the race coefficient from (1) for a variety of different population subsamples. These results include the same set of controls as used in row 7 of Table 2 . The results indicate that the racial difference in visible consumption remains large among the sub samples of single men, single women, and married households. For example, Black (Hispanic) single men consume 32 percent (40 percent) more visible goods than similar White single men. The

\footnotetext{
${ }^{17}$ When estimating this equation, we restrict the sample to those with positive current household income. We then truncated current income for both samples at $99^{\text {th }}$ percentile of black distribution (which was roughly $\$ 100,000$ ). Engel curves for both Blacks and Whites in Figure 1 are thus up through $\$ 100,000$.

18 One question that we will continue to address throughout the paper is whether there are differences in "price" effects which cause Blacks to spend more on visible goods than comparable Whites. For example, if Blacks were discriminated against in the market for visible goods, Blacks with a given income would pay more for those items than comparable Whites. General discrimination cannot explain the results in Table 2 which control for total expenditures directly. As a result, the correct interpretation of our results should be why Blacks and Hispanics allocate a greater share of their expenditures to visible goods. There is no evidence that, relative to other goods, Blacks and Hispanics pay higher prices for clothing, jewelry, and personal care items than similar Whites.
} 
comparable differences for Black and Hispanic single women, relative to White single women, were 29 percent and 24 percent, respectively.

Rows 4-7 of Table 3 show the racial gap in visible consumption within different educational groups. We find racial differences in visible consumption within all educational groups, although the magnitudes of the differences vary slightly for different education levels. Black households headed by someone with only a high school degree consume 38 percent more visible goods than a comparable White household, conditional on income, total expenditure and demographics. The comparable Black-White gap in visible expenditures for households headed by someone with at least a college degree is 28 percent. The gradient in the racial gap in visible consumption with respect to education is steeper between Whites and Hispanics. Among households headed by a person with only a high school degree, Hispanics consume 32 percent more visible goods than comparable Whites. Among college graduates, the gap falls to 12 percent.

In Rows $8-10$ of Table 3, we explore how the racial gap in visible expenditures changes with age. On average, the gap in visible expenditures found among 18-34 years is nearly identical - for both Blacks and Hispanics - to the racial gap found among 35-49 year olds. Using fine age ranges up through the age of 49 , the same patterns hold. However, as seen in Row 10, for Black households older than 49, the racial gap starts to diminish sharply. Specifically, for households between 50 and 69, Blacks consume only 22 percent more visible goods than comparable Whites. As noted earlier, all households spend less on visible goods as they age. The racial gap in visible consumption in absolute dollars therefore declines monotonically with age.

Although we do not present the results in Table 3, we find that the racial gap in visible consumption has been consistently present during the period between 1986 and 2002. For example, the racial gap in visible consumption between Blacks and Whites for our main analysis sample, conditional on income, expenditure, and demographics, was 31 percent for the sub-period 
of 1990-1993 and was 29 percent for the sub-period of 1999-2002. ${ }^{19}$ Additionally, we found no difference in the estimated race coefficients within a sample of renters and a sample of home owners. Black renters (home owners) consumed roughly 30 percent more visible goods than White renters (home owners), all else equal. Lastly, the racial differences were robust to splitting the sample on the head's current employment status.

Table 4 shows that Blacks and Hispanics spend much more than their White counterparts on each of the visible consumption categories - vehicles, clothing, and personal care. Panel A shows results for the full sample, while Panel B is for a sample of households who own a vehicle. In both of the samples, Blacks and Hispanics spend significantly more on both personal care and clothing and jewelry than comparable Whites. Vehicle spending differences, however, only occur among vehicle owners. Moreover, the vehicle differences are only statistically significant with the expanded measure of vehicle spending which includes both only spending on the vehicle itself at the time of purchase (the limited vehicle measure), and also spending on customization and monthly principle payments on the vehicle loan. The data appendix outlines the categories in the limited and expanded vehicle measures.

The fact that Blacks and Hispanics, all else equal, have a lower probably of vehicle ownership explains why the racial difference in vehicle spending is not found for the full sample. The lower vehicle ownership among Blacks and Hispanics is likely the result of two factors. First, Blacks and Hispanics are more likely to live in city centers and, as a result, have lower vehicle needs. Second, liquidity constraints may prevent Blacks and Hispanics from making a sufficient down payment to purchase a vehicle. Among, vehicle owners, however, Blacks spend 15 percent more on vehicles (including customization) than comparable Whites. ${ }^{20}$

\footnotetext{
${ }^{19}$ Also, while our analysis focuses on the period since 1990, we used the 1960-61 CEX survey to examine historical racial differences in visible expenditure. Our results cannot reject the hypothesis that the Black/White difference in that earlier period is identical to the gap in the period we study.

20 We have also conducted a similar analysis using PSID data to explore differences in vehicle wealth holdings between Blacks and Whites. The PSID tracks the value of the household vehicle wealth (cars, trucks, motorcycles, etc.) at their re-sale value. This measure includes the value of all car accessories (tires, rims, etc.). Blacks, conditional
} 
If minority households spend more on visible goods relative to White households with similar income, total expenditures, and demographics, on what expenditures are they spending less? The inter-temporal budget constraint implies that this higher spending must come either from another component of current consumption or from future consumption (i.e. current savings). Table 5 looks at the conditional differences in spending on other consumption categories. These consumption categories - along with visible consumption - comprise the universe of consumption expenditures in the CEX and are described in Appendix Table A1. The coefficients in Table 5 come from a regression similar to (1) where the dependent variable of log visible expenditures is replaced by the log of other different consumption categories. Otherwise, the regression is exactly the same as the one reported in row 7 of Table 2 . As indicated in the notes to Table 5, for expenditure categories for which there was a high incidence of zero expenditure, we estimate Tobit regressions.

The first striking fact from Table 5 is that there is no evidence that Blacks and Hispanic consume a higher percentage of their spending than Whites on any other consumption category except for visible goods and housing. In fact, aside from housing, Blacks spend less than similar Whites on all other consumption categories. Some of the differences are small. For example, there only appears to be very small differences between Blacks and Whites in food expenditures. However, Blacks spend 17 percent less on education, approximately 50 percent less on entertainment, and 56 percent less on health spending. Similar patterns emerge for Hispanics.

Both Blacks and Hispanics spend slightly more on housing expenditures for shelter and utilities than their White counterparts, while at the same time spending much less on home furnishings. ${ }^{21}$ As we have noted, housing may itself be a visible good which would explain why it is associated with similar expenditure patterns to those for jewelry, clothing and vehicles.

on five year average income, demographics, and total wealth, have roughly 15 percent more vehicle wealth than Whites. These results are consistent with the results shown in Table 5.

${ }^{21}$ The utility category is driven to a large extent by differences in telephone expenditures (including cell phones and pagers). 
However, as discussed above, it is also possible that there is differential treatment by race in the housing market. To provide conservative estimates of conspicuous spending differences, we exclude housing from our measure of visible goods.

The results presented thus far are from the CEX, the primary source of information on consumption expenditure. Despite its excellent coverage of consumption behavior over a long time, it is not designed to measure household income. To confirm the basic patterns presented above, we have also examined racial consumption expenditure differences using data from the PSID. This finding increased our confidence that total expenditure in the CEX is a good proxy for permanent income. Although the PSID is not designed to measure consumption and has historically had information on only a limited set of consumption measures, the survey has recently (in 2005) added an expanded set of expenditure questions, including questions about the visible items we study. The PSID expenditure measures are available for only one or two years, and are obviously not as complete as the CEX measures. On the other hand, the PSID does have much more detailed information on income than the CEX. We do not present the results here, but the basic patterns about racial differences in visible expenditure documented above are also found in the PSID.

In summary, we show in this section that Blacks and Hispanics spend roughly 30 percent more on visible expenditures (cars, clothing, jewelry, and personal care items) than otherwise similar Whites. These patterns are similar across all sub groups of the population, with the notable exception that the differential racial propensity to consume visibly declines sharply with age. Finally, while minority households consume much more visible goods than comparable Whites, they consume less than or the same amount as Whites of all other consumption categories aside from housing.

\section{Theories of Conspicuous Consumption}

What explains the differences in visible spending between races presented above? One possible answer is that Blacks and Hispanics simply like to consume the kinds of goods we 
classify as visible more than their White counterparts. Given the fact that racial groups exhibit such different tastes with respect to matters as diverse as cuisine, music, and even popular entertainment, it is likely that the conspicuous consumption differences documented above reflect, in part, differences across cultures in the their tastes for these different types of goods. Unfortunately, a "cultural difference" explanation has the drawbacks that it is essentially tautological and that it does not provide additional predictions that can be tested in the data.

We believe that existing theory points to an alternative explanation for observed consumption which does not rely on Blacks and Hispanics having stronger preferences for visible goods. Following Veblen (1899) and Smith (1759), a large theoretical literature in the social sciences has focused on the idea that individuals care about their status in society. Conspicuous consumption in these models affects status by communicating information about unobserved economic position within the particular group. Different types of status models have been proposed in the literature, but we focus here on a signaling framework. ${ }^{22}$ This type of model is straightforward and familiar, and its key predictions are, in most cases, very similar to other status models such as those that focus on relative consumption. ${ }^{23}$

To see the main insights from a signaling representation of status, consider a relatively general and simple static framework of a social group $G$ consisting of households with incomes $y^{i}$ distributed continuously over some range with mean $\mu_{G}$. Suppose that all individuals in group $G$ have identical preferences defined over two consumption goods and over status, given by

$$
u\left(y^{i}-c\right)+\alpha u\left(c^{i}\right)+s
$$

where $u$ is an increasing and concave function; $c$ is conspicuous (visible) consumption; $y$-c represents consumption which is not (easily) visible or conspicuous to outsiders such as food,

\footnotetext{
${ }^{22}$ Signaling formulations of status have been presented by, among others, Ireland (1994), Cole et al (1995), Bagwell and Bernheim (1996), Glazer and Konrad (1996), and Corneo and Jeanne (1998).

${ }^{23}$ Duesenberry (1949), Pollack (1976) and Frank (1985) developed early models of the relative consumption class. Most recently Hopkins and Kornienko (2004) and Becker and Rayo (2006) analyze the welfare implications of this type of preference specifications.
} 
health, or saving; and $s$ represents status.

In a signaling framework, it is natural to represent individual $i$ 's status as reflecting how a given trait of his compares to some standard. Assume that this unobserved trait is income. In assigning status to an individual, outsiders have two bits of information: the person's visible consumption, and what is known about the income of the group from which the person is drawn in the most simple case, the mean of group income $\mu_{G}$. In equilibrium, the inferences made about a person's income are correct, so that observed levels of visible consumption are associated with particular income levels. The status a person receives in equilibrium is, in general, given by $^{24}$

$$
s^{i}=s\left(c^{i}, \mu_{G}\right)
$$

Since, in equilibrium, more visible consumption is associated with higher levels of inferred income and thus with higher status, the partial derivative of status with respect to visible consumption expenditure $c$ is positive, or $s_{c}>0$. The partial derivative of status with respect to mean group income, $s_{\mu}$, is less clear, and depends on the specific formulation of status assumed and the nature of the equilibrium status assignment. ${ }^{25}$

Let $c^{*}\left(y^{i}, \mu_{G}\right)$ be person $i$ 's equilibrium level of visible consumption, where $y^{i}$ is his income. Equilibrium consumption is determined by maximizing (2) subject to a budget set and thus is the solution to the first order condition:

$$
s_{c}\left(c^{*}, \mu_{G}\right)=u^{\prime}\left(y^{i}-c^{*}\right)-\alpha u^{\prime}\left(c^{*}\right) .
$$

\footnotetext{
${ }^{24}$ In general, equilibrium status can also depend on higher moments of the income distribution, such as the variance. For example, this will be the case when status is proportional to income or consumption rank. In addition, variance of group income will matter in a pure signaling model, but its contribution is hard to disentangle from that of the mean.

${ }^{25}$ In general, the relationship between status and average group income hinges on the specific assumption made about status formation in the model. It is most often assumed that individuals care about how their income is thought to compare to others in their group, implying that $s_{\mu}<0$. However, Ireland (1994)) presents a model in which simply belonging to a richer reference group confers higher status, so that $s_{\mu}>0$.
} 
Two implications are immediately forthcoming from this condition. First, conspicuous consumption is greater than would be true if there were no status concerns. Second, and of important predictive value, is that conspicuous consumption should be increasing in own income. $^{26}$

Differentiating both sides of the first order condition (3) with respect to $\mu_{G}$ yields

$$
s_{c \mu}\left(c^{*}, \mu_{G}\right)=-c_{\mu_{G}}^{*}\left(y^{i}, \mu_{G}\right)\left[u^{\prime \prime}\left(y^{i}-c^{*}\right)+\alpha u^{\prime \prime}\left(c^{*}\right)+s_{c c}\left(c^{*}, \mu\right)\right]
$$

The second order condition for $c^{*}$ implies that the expression in the square brackets is negative in (4). Thus, the partial effect of mean group income on equilibrium visible consumption, $c_{\mu_{G}}^{*}$, is of the same sign as the second derivative of status function, $s_{c \mu}$ : holding own income constant, conspicuous consumption is decreasing in mean group income if $s_{c \mu}<0$, and is increasing if the inequality is reversed.

What, intuitively, does the second derivative $S_{c \mu}$ mean and what is its likely sign? Technically, $s_{c \mu}$ measures whether the positive increment to his status that an individual receives by engaging in marginally more visible expenditure is bigger or smaller when his group has slightly higher average income. It should be clear that the sign of $s_{c \mu}$ will depend on how specifically status is modeled. Notice, however, that in perhaps the most simple type of status representation possible, in which the status conferred upon an individual is simply how his income compares (or is thought to compare) to the average income of the group, then $s_{c \mu}<0$, and equilibrium consumption will be decreasing in average group income. Intuitively, in this most simple case, the richer the group is on average, the less an individual gains relative to the

\footnotetext{
${ }^{26}$ These are standard predictions of signaling models. See Ireland (!994) or Cole et. al. (1995) for a formal discussion.
} 
mean from a one dollar increase in visible consumption. The marginal return to status "spending" in the form of higher visible spending falls as the average group income rises.

The condition that $s_{c \mu}<0$ holds for many representations of relative status and concave utility functions, $u$. Indeed, some empirical tests in the literature find that subjective well being, which is presumably positively related to status, falls when average reference group income rises. Conspicuous consumption is not directly the focus of these papers, but if their results were put into a conspicuous consumption context, their findings would imply that $s_{c \mu}<0 .{ }^{27}$ In the Theory Appendix, we briefly work through a specific parametric example of log linear utility with status defined as the ratio of expected income (given consumption) to average reference group income.

Although we have focused on the signaling version of the relative status model, the results above are consistent with a model where status is explicitly based on conspicuous consumption. For example, Becker and Rayo (2006) study a model in which status is given by the individual's position in the distribution of durable good expenditures and show that in equilibrium this position corresponds to the position in the income distribution. As with the signaling model, equilibrium status depends on the moments of the reference group income distribution (especially the mean), and on the individual choice of conspicuous consumption. We do not attempt to distinguish between these theoretical formulations of status in this paper, especially in light of their similar predictions.

If a relative status consideration of the sort outlined above partly determines consumption decisions, it follows that persons with exactly the same preferences and with the same income but who belong to different social groups will consume different amounts of visible goods if the mean incomes of their groups are different. In particular, visible spending should be lower for individuals in the group with higher mean income. Can a simple model of conspicuous

\footnotetext{
${ }^{27}$ Recent examples on relative status and subjective well being include McBride (2001) and Dynan and Ravina (2007)
} 
consumption where status depends on expected income relative to the mean income of a reference group reconcile the results presented above? We turn to this in the next section.

\section{5: $\quad$ Empirical Tests of Conspicuous Consumption Model}

\section{Explaining Within Race Conspicuous Consumption Differences}

The foregoing discussion said nothing about race specifically, but we argue that the longstanding cultural separation of races in the U.S, combined with high levels of residential segregation, suggest that race partly determines a person's reference group, $G$. In addition, there is likely a spatial dimension to reference groups: it seems quite unlikely that the consumption patterns of individuals on one coast of the country should be informed by considerations about persons living on the opposite coast, even if those others are of the same race. In all that follows, we therefore suppose that reference groups are the interaction of race and space: persons of an individual's own race, living is his own state. We define reference groups with respect to state because the state is lowest level of spatial aggregation available in our data.

One interesting implication of acknowledging the likely spatial component of reference groups is that we can assess the validity of the status model's main predictions not only across different races, but also with data on individuals of the same race. That is, we ask: Among persons of a given race, are those from areas with higher average income less likely to engage in conspicuous consumption, as the simple relative status model would suggest?

We focus first on visible consumption among White households. On a sample of Whites we estimate the regression:

$$
\ln \left(\text { visible }_{i}\right)=\beta_{0}+\Gamma_{j} \text { State }_{j}+\gamma \text { Income }_{i}+\varphi \text { Expenditure }_{i}+\theta X_{i}+\eta_{i}
$$

where State $_{j}$ is a vector of state dummies and $\Gamma_{j}$ is the vector of coefficients on those state dummies. Otherwise, the controls are identical to those used in Row 7 of Table 2, and the sample restrictions are the same as discussed above. 
Figure 2a plots the coefficients on the state dummies $\left(\Gamma_{j}\right)$ from a regression such as $(5)$ against the mean income of White males from state $j$. We use data from the 1990 through the 2002 March Current Population Surveys (CPS) to compute the mean labor income of White males by state. ${ }^{28}$ We use the CPS to compute our measure of the mean income of the reference group within each state as opposed to the CEX data because of both the large sample sizes available in the CPS and the better quality income data.

Figure $2 \mathrm{a}$ shows that there is a strong negative relationship between the propensity of White households to consume visible goods and the mean income of White men in the state. Alabama was the omitted state in the estimation of (5). Figure 2a shows that, holding own income, total expenditure, and demographics constant, White Texans consume 20 percentage points less visible goods than White Alabamans. The mean income of households headed by White men in Texas is nearly $\$ 10,000$ a year higher than the mean income of households headed by White men in Alabama. The regression line in the figure is from a regression which is weighted by the number of CPS observations from the state. The negative and strongly statistically significant regression coefficient implies that, on average, increasing mean state income by $\$ 10,000$ reduces the amount of visible consumption by 17 percentage points, all else equal. Lastly, the R-squared of the regression of the state visible expenditure fixed effect against mean state income among Whites is 0.35 .

One concern about the results in the Figure 2a is that there may be some factor which is correlated with average state income, which mechanically causes reduced spending on visible goods. Differences across states in housing prices represent one main concern here. Consider a state where the price of housing is high, all else equal. Individuals with a given level of income in that state will spend more for the same amount of housing, and less on other consumption

\footnotetext{
${ }^{28}$ The labor income of adult men of a person's state*race cell is our main measure of average reference group income. However, we tried several alternative measures for reference group income, including total family income and total family labor of all persons of the individual's race*state cell. In all that follows, the results are essentially unchanged under these alternative income specifications.
} 
items including perhaps visible items. To examine the relationship between housing expenditures and mean state income, we re-estimate (5) with the household's housing outlays as the dependent variable. Figure $2 b$, which plots the estimated state effects from this regression, shows that household housing outlays are indeed much higher in states with high mean state income.

Are the results in Figure 2a driven by differences in housing expenditures across states? We re-estimated (5) for visible spending but add the household's housing expenditures as an additional regressor. The estimated state fixed effects are then plotted against state income in Figure 2c. The figure shows that housing expenditure differences explain no more than twenty percent of the negative relationship between visible expenditures and mean state income documented in Figure 2a. We find that a $\$ 10,000$ increase in mean state income reduces visible expenditure purchases by a strongly statistically significant 13 percent. There is thus a strong negative relationship between visible spending and mean state income among Whites even after controlling for differences in housing expenditures.

Apart from the concern that state level differences in housing cost could account for the patterns we observe for visible goods, there is still the possibility that a state's level of income might be related to the menu of prices its residents pay for different consumption items. For example, the presence or generosity of transfer programs or of other consumption insurance schemes might vary with a state's average level of income. If this were so, persons with the same level of income in different states would effectively pay different prices for and consume different amounts of various consumption items in the different states. In particular, we would expect to find a negative pattern between state income and levels of expenditures for other items.

Figures $2 \mathrm{~d}-2 \mathrm{f}$ depict patterns analogous to those in Figure $2 \mathrm{c}$ for expenditures on food, entertainment and all non-housing/non-visible expenditures, respectively, after controlling for differences in housing expenses. In stark contrast to the results for visible goods, we find no evidence of a negative relationship between state income and these expenditures among Whites. 
Indeed, food expenditures increase slightly with state income for Whites. For entertainment service and all non-housing/non-visible expenditures there is no difference in Whites' propensity to spend on these items across states with different levels of income. Overall, for Whites, the negative relationship between visible expenditures and mean state income does not exist for any other category of expenditures. These results provide strong support for our model's conjecture that visible spending is negatively related to the economic status of one's peers, holding individual characteristics constant.

The regression analog of $(5)$ is:

$$
\ln \left(\text { visible }_{i}\right)=\beta_{0}+\delta \ln \left(\mu_{G}\right)+\gamma \text { Income }_{i}+\varphi \text { Expenditure }_{i}+\theta X_{i}+\eta_{i}
$$

where the state dummies are replaced by the mean labor income of White men in the state, $\mu_{G}$. Table 6 shows the results from this regression. Column 1 of Table 6 shows that the base estimate of $\delta$ is a strongly statistically significant -0.94 . This implies that doubling mean state income of White men reduces visible expenditures of Whites by 94 percent, all else equal. This coefficient roughly translates to the relationship between the state fixed effect and mean state income estimated in Figure 2a.

In column 2 of Table 6, we include housing expenditures as an additional control and the coefficient still remains large and statistically different from zero. In column 3, we include the mean income of all men in the state (not just Whites) as an additional control. The discussion in the preceding section suggests that households' visible spending should respond negatively to the mean income level of their reference group. If reference groups are defined along racial lines, households' visible consumption should not be related to the mean income of other racial groups within their state. The evidence in column 3 weakly supports this. White men do respond statistically to the mean income of White men, but there is no statistical relationship between their consumption and the mean income of other racial groups in the state. The standard errors are such that we cannot rule out that the coefficient on the income of White men (row 1) is 
statistically different from the coefficient on the income of all men (row 3) - an unsurprising result since white Men constitute the over-whelming majority of men in all states.

In column 4 of Table 6 we also include measures of the log of the standard deviation of the income of White men in state $j$ relative to the mean income of White men in state $\mathrm{j}$ as an additional control. In this specification, the estimate on the variance is negative, which implies that a more disperse population weakens the propensity to consume visibly, all else equal. ${ }^{29}$ Notice, all the other coefficients remain constant between the specifications shown in columns 2 and 4 .

Table 7 shows that the same patterns hold within samples of Blacks and Hispanics. Specifically, we re-estimate an equation similar to (6), in turn, on samples of only Blacks (column 1 of Table 7); only Hispanics (column 2 of Table 7); and a a pooled sample of Blacks and Hispanics (column 3-6 of Table 7). In column 1 (2), our measure of $\mu_{G}$ is the mean income of Black (Hispanic) males in state $j$. In the pooled regression in column $3, \mu_{G}$ is the mean income of either Black men in state $j$ if the household head is Black or the mean income of Hispanic men in state $j$ if the household head is Hispanic. The results show that for both the Black and the Hispanic samples, the estimated effect of $\mu_{G}$ is negative and large. The coefficients on $\mu_{G}$ for Blacks (Hispanics) imply that a doubling of mean state income of the race based reference group leads to a 48 (76) percent decline in the propensity to spend on visible goods, all else equal. The results are nearly identical in the pooled regression, although the coefficients are much more precisely estimated. A doubling of the mean income of a person's reference group within their state results in a 56 percent reduction in visible spending (p-value $<$ $0.01)$.

In column 4, we include log housing expenditures as an additional control. The results are robust to this inclusion. A doubling of mean income of the reference group within the state

${ }^{29}$ This is consistent with some versions of the status signaling model (e.g. Cole et. al. (1995)). 
results in a 37 percent reduction in visible spending. Notice, that this number is not too different from the corresponding estimate among White men (Table 6 column 3). In column 5 of Table 7, we also include the mean income of all men in the state as an additional regressor. We find that Blacks and Hispanics have lower visible expenditures when the mean income of their race-based reference group is higher. However, if the mean income of all men in the state increases holding the mean income of men from the person's own race constant, visible expenditures increase.

In column 6 , we also add a measure of the standard deviation of income within the state relative to mean income within the state (by race). The relative standard deviation measure is positive, but not statistically different from zero. Although not shown, we also find no relationship between food and entertainment spending and mean own group state income among Blacks and Hispanics. ${ }^{30}$

Overall, the within-race results are strongly consistent with the status model of conspicuous consumption outlined above. If the mean income of those of a person's own race within their state increases, the person's spends less on visible expenditures, all else equal. This fact is found among Whites, among Blacks and among Hispanics and persists even after controlling for differences in housing expenditures across states.

\section{B. $\quad$ Explaining Racial Differences in Visible Expenditures}

We analyze next whether the racial differences in visible consumption presented earlier in the paper can be reconciled by a status model with the key features described in the previous section. We estimate:

\footnotetext{
${ }^{30}$ One implementation of our notion of reference groups is that it is defined as one's neighborhood. The use of mean Black income within the state as a reference group for Blacks and mean White income within the state a reference group for Whites, under this interpretation, assumes that Blacks live around Blacks and Whites live around Whites. While it is has been shown that there is substantial segregation by race in residential living patterns (see, for example, Cutler et al. (1999)), residential sorting by race is far from perfect. As a result, actual sorting patterns pose another interesting question: Do Blacks who live in "blacker" communities respond more to mean Black income than Blacks who live in "whiter" communities? We tested this prediction by aggregating up to the state level the metropolitan measures of segregation compiled by Culter et al. (1999) and interacting measures of segregation with mean state income of Blacks in the estimation shown in Table 7 (for a sample that only included Blacks and Whites). The segregation interactions came with the predicted sign (Blacks in more segregated states responded more to mean Black income), but the standard errors were much too large to say anything definitive.
} 


$$
\begin{aligned}
\ln \left(\text { visible }_{i}\right)= & \beta_{0}+\beta_{1} \text { Black }_{i}+\beta_{2} \text { Hispanic }_{i}+\delta \ln \left(\mu_{G}\right) \\
& \gamma \text { Income }_{i}+\varphi \text { Expenditure }_{i}+\theta X_{i}+\eta_{i}
\end{aligned}
$$

Equation (7) is identical to (1) except for the inclusion of $\ln \left(\mu_{G}\right)$ as an additional regressor where $\mu_{G}$ is the mean level of the individual's racial group in state $j$. This regression assesses whether Blacks or Hispanics, holding their own income and the mean income of the racial peer group constant, have the same visible expenditures as Whites, all else equal. The results are shown in Table 8. Column 1 re-displays the results from row 7 of Table 2 (without including $\ln (\mu)$ as a control). As shown earlier, without reference group income controls, observationally equivalent Blacks and Hispanics male-headed households consume 32 and 31 percent more on visible goods, respectively, than Whites.

The regression presented in column 2 continues to exclude reference group income but now adds state fixed effects. The estimated effects of around 0.35 show that the state fixed effects have essentially no influence on the estimated racial gaps in visible expenditures. In the third column we add the measure of average reference group income and exclude the state fixed effects. Recall, $\mu_{G}$ measures the average income of the household's race/state group. This regression shows dramatically that our control for reference group income explains nearly the entire gap in spending across races. The estimated Black coefficient falls from a strongly significant 0.32 to a statistically insignificant -0.09 , once reference group mean income is accounted for. Similarly the Hispanic dummy, which was originally from 0.31 , essentially vanishes statistically. Column 4 adds state fixed effects to the regression in the third column, and the fifth column adds both state fixed effects and the standard deviation of the income of the reference group. In both of these regressions, the results are qualitatively the same as the results in column 3. In summary, these results show dramatically that the visible expenditure between Blacks and Hispanics versus Whites vanishes once we account for reference group characteristics. Importantly, the results also indicate that it is not some generic trait of the state 
that explains the conspicuous consumption gap, but rather the incomes of individuals' racial reference groups specifically.

On the whole, these results are strongly consistent with the predictions of the class of models of status and conspicuous consumption discussed in section 4. The key point is that a very simple status model appears to explain differences in individual visible consumption within and across races, and does so without requiring that there be systematic differences in preferences by race. The only role plaid by race is in determining one's reference group.

\section{Conspicuous Consumption Implications}

In this section, we empirically explore the implications of conspicuous consumption for explaining racial differences in educational spending, health care spending, and savings. By the definition of the inter-temporal budget constraints, higher current spending on conspicuous items must be associated with lower current spending on other consumption items and/or in lower savings and, consequently, lower consumption in the future.

To begin, we explore how much of the racial differences in other consumption categories can be explained by racial differences in spending on visible goods. To do this, we re-estimate the regressions in Table 5 with two additional controls: the share of total spending allocated to housing and the share of spending allocated to visible goods. We use the share variables so as not to confound the fact that the levels of spending within almost all broad consumption categories increase with income. Given that income and total expenditure controls were already included in our estimation of the results in Table 5, adding the share variables answers the thought experiment: holding income and total expenditure constant, what happens to spending on other consumption categories if the share of expenditure to either housing or visible goods increases?

These regression results are shown in Table 9. Panels A, B, and C present results for spending on education spending, health care, and food, respectively. Our baselines specifications 
are regressions of the log of spending within the consumption category (e.g., education, health, food) on the full set of income, expenditure, and demographic controls used in the estimate presented in Table 5, along with a Black and Hispanic dummy variable. The table presents only the coefficients on the Black and Hispanic dummies. For ease of comparison, we re-display our baseline results in Rows "1" of Table 9.

Rows 2 of Table 9 include the housing share of expenditures as an additional control. We include the housing share of expenditure to account for potential differences in housing costs between races of similar income and demographics because of potential discrimination in housing markets. For the most part, including differences in housing expenditures explains little of the racial gaps in education, health care, and food spending. Specifically, after controlling for housing expenditures, Blacks still spend 20 percent less on education and 56 percent less on health care than comparable Whites. And as in Table 5, there still remains a 7 percent difference in food spending between similar Blacks and Whites once conditioning on housing expenditures.

By contrast, including controls for the share of spending on visible goods explains a significant amount of the racial spending gap in health care and education for both Blacks and Hispanics. The Black-White gap in education gap falls to zero (nearly 25 percentage points) and the Black-White gap in health care falls by 14 percent (nearly 8 percentage points) after controlling for differences in spending on conspicuous goods.

We also explore racial differences in food and housing spending after controlling for differences in spending on visible goods. Controlling for differences in the share of expenditures allocated to visible goods, we find that the Black propensity to consume food and housing, relative to similar Whites, increases by 4 and 6 percentage points respectively. The comparable increases for Hispanics were 3 and 5 percentage points.

Appendix Table A4 shows that the average quarterly spending on education, health care, food and housing for Whites in our sample were, respectively, \$288, \$464, \$1,733, and \$2,670. The estimates in Table 9 imply that the increased spending on visible consumption results in 
about $\$ 72$ less spending per quarter on education by Blacks $(0.25 * 288)$, about $\$ 37$ less spending per quarter on health care by Blacks $(0.08 * \$ 464)$, about $\$ 69$ less spending per quarter on food by Blacks $(0.04 * \$ 1,733)$, and about $\$ 160$ less spending per quarter on housing by Blacks $(0.06 *$ \$2,670), compared to otherwise similar Whites.

In total, our estimates imply that minorities spend about $\$ 1,350$ less per year on these four consumption categories. In the previous section, we found that Blacks spent an additional $\$ 2,300$ on visible goods compared to similar Whites. The results in Table 9 suggest that nearly sixty percent of this increased spending on visible goods represents resources diverted from spending on education, health care, food and housing compared to similar Whites. This implies that policies that try to eradicate the racial gaps in spending on these categories must recognize that the differences exist partly because of households' (potentially optimal) decision to consume conspicuously.

Finally, we examine how conspicuous consumption affects differences in savings behaviors across races. It is not obvious that there should be an effect of conspicuous spending on savings. For there to be such an effect it would have to be the case that the importance of status considerations diminishes with age, so that households would want to borrow against their future income to engage in more of it when young. ${ }^{31}$ Recall our earlier results indicated that, for all households, visible goods consumption does indeed fall with age. To explore the effect on savings, we use data from the Panel Study of Income Dynamics (PSID) - a survey with detailed information on household wealth holdings, very accurate information about household income over multiple periods, and easily accessible identifiers for the households' state of residence.

Row 1 of Table 10 shows the raw mean difference in wealth holdings between Blacks and Whites in the 1999 wave of the PSID. This wealth measure is total net worth which includes

\footnotetext{
31 Corneo and Jeanne (1998) and Becker and Rayo (2006) discuss the conditions under which conspicuous consumption lowers saving.
} 
housing wealth but not private or public pension wealth. ${ }^{32}$ The unconditional wealth gap of nearly $\$ 100,000$ is in line with previous estimates. Controlling for permanent income using a cubic in five year average income, education and a rich set of demographics explains roughly 60 percent of the unconditional racial gap in wealth holdings. This estimate of how much of the gap permanent income and demographics explain is consistent with results in the literature (Bound et al. (2002)).

The regression in the third row adds state fixed effects. Adding these controls leaves the measured wealth gap essentially unchanged. In row 4, we add the log of reference group income $\mu_{G}$. Controlling for the mean income of one's reference group at the state/race level dramatically reduces the measured difference in wealth holdings between similar Blacks and Whites. Specifically, roughly $60 \%$ of the unexplained racial gap in wealth holdings after controlling for permanent income and demographics is accounted for by average differences in reference group income. We do not wish to make a strong causal claim about the results in Table 10, however it does appear that the mechanism that leads Blacks to consume more conspicuous goods than their White counter parts could also explain some of the well documented BlackWhite wealth gap.

\section{Conclusion}

This paper contributes to the study of household consumption on several levels. We have documented the divergent patterns of expenditure on visible consumption goods across races. Consistent with popular perception, we find that minorities spend more on conspicuous items than Whites, controlling for differences in income. A variety of estimates show that these visible expenditure differences are relatively large and are associated with substantial diversion of

\footnotetext{
${ }^{32}$ See Hurst et al 1996 for a full description of the PSID net worth measure
} 
resources from other uses, including savings and expenditures on things like health care and education.

We argue that one does not need to appeal to cultural differences or racial differences in preferences to understand this evidence. We present a theoretical treatment of status-seeking and conspicuous consumption. A large subset of such models shares the prediction that visible consumption should vary negatively with the mean income of the individual's reference group. We show that visible consumption patterns both within and across races are consistent with this prediction. It is important to note, however, that there may yet be racial differences in utility parameters which act in combination with the effects we have identified.

The visible consumption items we study are almost surely not the only mechanism that individuals use to signal their economic position or which they like to consume as much others in their reference group. The items we study are probably most important for random, anonymous interactions in society and not for status forthcoming from interaction with friends, family members or colleagues. If consumption communicates information to these intimates it is likely to be consumption in the form of things like home furnishings, gas grills and entertainment durables, or spending on children's education which only intimates have the opportunity to observe. If would be interesting in future work to study which specific types of conspicuous consumption matter in which contexts.

Our analysis treats reference groups as being the interaction of race and state cells. This is partially justified on the grounds that there remains significant residential segregation in the U.S. At the same time, the presence of that segregation may mean that, contrary to our implicit assumption throughout, people's reference groups consist merely of those of who live around them, and that social networks are truly color blind. This is an interesting question for future work. Also interesting is the issue of the degree to which people choose their neighbors with an eye to satisfying the status considerations that we have identified. 
We believe that there are many implications of our results. For one thing, we show in the theoretical discussion that the prediction that conspicuous spending varies negatively with reference group income depends on a specific assumption about how the marginal status return varies with group income. Our results lend support for this way of representing status in future analyses. In addition, the finding that reference-group considerations matter for consumption behavior suggests that other aspects of household financial behavior beyond consumption and saving decisions may be similarly affected. For example, there may be different attitudes towards idiosyncratic risks and risks that are common to the individual's reference group, with implications for gambling behavior and under-diversification of investment portfolios, as explored in Roussanov (2007).

Also, the support that our results yield to the status-based view of conspicuous consumption has implication for welfare and policy design. Status-signaling models imply equilibrium over-consumption of visible goods at the expense of possibly inefficient reduction in other outlays, such as those financing education, health, and saving. One consequence is that the provision of certain benefits in kind (such as those associated with health care and education expenditures) might lead to a superior outcome than that attained through monetary transfers. At the same time, participation in means-tested social programs, if observable, is a signal associated with being a poor type, giving rise to a stigma attached to such programs. Ireland (1994) provides a careful analysis of these issues. Combining these theoretical insights with the empirical understanding of status seeking is a promising area of future research that should help to provide quantitative evaluation of various social programs.

Finally, the hypothesis that the desire for social status can explain various economic behaviors is found frequently within the social sciences. For example, Bloch et al. (2003) argue that the desire to signal social status can explain differences across households in their spending on wedding celebrations in rural India. Chung and Fisher (2001) explore the conspicuous spending patterns of recent immigrants into Canada. Frank (2000) makes a forceful argument that 
conspicuous consumption is a key driver of household expenditures and (under-) saving in the U.S. We believe that the mechanism we have highlighted may yield valuable insights about behavior of individuals within a variety of social and economic settings. 


\section{References}

Alexis, Marcus 1970, Patterns of Black Consumption: 1935-1960, Journal of Black Studies 1, 5574.

Bagwell, Laurie Simon, and B. Douglas Bernheim, 1996, Veblen effects in a theory of conspicuous consumption, American Economic Review 86, 349-73.

Becker, Gary S., Kevin M. Murphy, and Ivan Werning, 2005, The equilibrium distribution of income and the market for status, Journal of Political Economy 113, 282-310.

Becker, Gary S., and Luis Rayo, 2006, Peer Comparisons and Consumer Debt, The University of Chicago Law Review, 73, 231-248.

Bloch, Francis, Vijayendra Rao, and Sonalde Desai, 2004, Wedding Celebrations as conspicuous consumption: Signaling social status in rural India, Journal of Human Resources, 39(3), 675-95.

Bound, John, Robert Barsky, Kerwin Charles, Joseph Lupton, 2002, Accounting for the BlackWhite Wealth Gap: A Non-Parametric Approach, The Journal of the American Statistical Association, 97, September, 663-673

Chambers, Jason, 2006. Equal in Every Way: African Americans, Consumption and Materialism from Reconstruction to the Civil Rights Movement, Advertising \& Soceity Review 7(1), online.

Charles, Kerwin Kofi and Erik Hurst, 2002, The Transition to Home Ownership and the BlackWhite Wealth Gap, The Review of Economics and Statistics, 84(2), 281-297.

Chung, Ed and Eileen Fischer 2001, When Conspicuous Consumption Becomes Inconspicuous: The Case of Migrant Hong Kong Consumers, Journal of Consumer Marketing, 18(6), 474-87.

Clark, Andrew E., and Andrew J. Oswald, 1996, Satisfaction and Comparison Income, Journal of Public Economics56, 359-381.

Cole, Harold, George Mailath, and Andrew Postlewaite, 1992, Social norms, savings behavior and growth, Journal of Political Economy 100, 1092-1126.

Cole, Harold, George Mailath, and Andrew Postlewaite, 1995, Incorporating concern for relative wealth into economic models, Federal Reserve Bank of Minneapolis Quarterly Review 13(9), 12 21.

Corneo, Giacomo, and Olivier Jeanne, 1998, Social organization, status, and savings behavior, Journal of Public Economics 70, 37-51.

Cutler, David \& Edward L. Glaeser \& Jacob L. Vigdor, 1999. "The Rise and Decline of the American Ghetto," Journal of Political Economy 107(3), 455-506.

Duesenberry, James S., 1949, Income, Saving, and the Theory of Consumer Behavior (Harvard University Press: Cambridge, MA). 
Dynan, Karen E. and Enrichetta Ravina, 2007, Increasing Income Inequality, External Habits, and Self-Reported Happiness, American Economic Review Papers and Proceedings 97(2): 226-231.

Frank, Robert H., 1985, The demand for unobservable and other nonpositional goods, American Economic Review 75, 101-116.

Glazer, Amihai and Kai Konrad, 1996, A signaling explanation for private charity, American Economic Review 86(4), 1019-1028.

Heffetz, Ori, 2007, Conspicuous Consumption and Expenditure Visibility: Measurement and Application, unpublished paper.

Hurst, Erik, Ming Ching Luoh, and Frank Stafford . 1998. "The Wealth Dynamics of American Families: 1984 - 1994”. Brookings Papers on Economic Activity, 98:1.

Hopkins, Ed, and Tatiana Kornienko, 2004, Running to Keep in the Same Place: Consumer Choice as a Game of Status, American Economic Review 94(4), 1085-1107.

Ireland, Norman, 1994, On Limiting the Market for Status Signals, Journal of Public Economics, $53,91-110$.

Kahneman, Daniel and Alan Krueger,2006, Developments in the Measurement of Subjective Well-Being, Journal of Economic Perspectives 20(1), 3-24.

Kapteyn, Arie, Peter Kooreman, Peter Kuhn, and Adriaan Soetevent, 2006, Measuring Social Interactions by Observing Neighbors of Lottery Prize Winners, Working Paper.

Lamont, Michele and Virag Molnar, 2001, How Blacks use consumption to shape their collective identity: Evidence from marketing specialists, Journal of Consumer Culture 1, 31-45.

Luttmer, Erzo. F. P., 2005, Neighbors as negatives: Relative earnings and well-being, Quarterly Journal of Economics 120, 963-1002.

McBride, Michael, 2001, Relative-income effects on subjective well-being in the cross-section, Journal of Economic Behavior \& Organization 45, 251-278.

Mullins, Paul 1999, Race and Genteel Consumer: Class and African-American Consumption, 1850-1930, Historical Archaeology 33(1), 22-38.

Munnell, Alicia H. \& Geoffrey M. B. Tootell \& Lynn E. Browne \& James McEneaney, 1996,Mortgage Lending in Boston: Interpreting HMDA Data, American Economic Review 86(1), $25-53$.

Pollack, Robert A, 1976, Interdependent preferences, American Economic Review 66, 309-20.

Ravina, Enrichetta, 2005, Habit Persistence and Keeping Up with the Joneses: Evidence from Micro Data, unpublished paper.

Roussanov, Nikolai, 2007, Diversification and its discontents: idiosyncratic and entrepreneurial risk in the quest for social status, unpublished paper. 
Sabelhaus, John and Ed Harris (2000). Consumer Expenditure Survey, Family-Level Extracts, 1980:1-1998:2, http:/www.nber.org/ces_cbo/Cexfam.doc

Smith, Adam, 1759, The Theory of Moral Sentiments. Repr., New Rochelle, NY: Arlington House, 1969.

Spence, Micheal. 1973. Job Market Signaling. The Quarterly Journal of Economics, Vol. 87(3), 355-374

Veblen, Thorstein, 1899, The theory of the leisure class: an economic study of institutions. Repr., Kila, MT: Kessinger, 2004. 


\section{Data Appendix}

For our primary analysis, we use the extracts of the Consumer Expenditure Survey (CEX), compiled by Harris and Sabelhaus and posted online by the National Bureau of Economic Research (NBER). ${ }^{33}$ The NBER CEX files are available from 1980Q1 - 2003Q1, and we use data from 1986 to 2002. 1986 is the first year that the CEX data included unique family identifiers, which we need to merge key additional information from the BLS's raw CEX data files. The NBER CEX extracts were intended to provide a condensed version of original data which was consistent over time. The extracts include information from the CEX family files, member files, the detailed expenditure files, and the detailed income files. The extracts aggregate spending over 500 detailed items in the raw data into 47 spending categories. Our analysis further aggregates spending into 15 categories, summarized in Appendix Table A1. The 15 categories we use in this paper is the universe of all expenditure categories in the NBER CEX files. We restricted the NBER-CEX data to include only household heads (ensuring that there was only one observation per household in our data). After deletions, our analysis sample included 48,758 households, comprised of 36,706 White households, 6,760 Black households, and 5,292 Hispanic households.

We briefly summarize any modification and restrictions we imposed on the data.

- The NBER CEX files do not include state of residence, Hispanic origin, city size, the number of adults in the household, and the number of quarters that the household participated in the survey. We downloaded these key variables from the CEX raw files and merged them in manually to the analysis sample.

- As is standard in the literature, we compute a measure of housing service flows. For renters, this is the rent for their home/apartment; for homeowners it is home owner's report of the rental equivalence of their home. In the analysis, we experimented with other measures of housing flow services, such as setting it to $6 \%$ of homeowner's housing value. The results were unaffected.

- The analysis uses two measures of vehicle spending: a "limited" measure which includes only net outlays (mostly down-payments) associated with the initial purchase of vehicle; and an "expanded" measure which includes the repayment of principle on vehicle loans, spending on maintenance, leasing, repairs, storage and rental, and spending on spending on tires, tubes, accessories and other parts.

- Our measure of housing services spending includes spending on the rental of household furniture and spending on home maintenance (such as paint, roof repair and replacement), home remodeling (adding an addition) and home decorating (wall to wall carpeting, replacement of hard wood floors). The inclusion of these categories is an artifact of the NBER CEX files. The measure of rent paid for tenant-occupied dwellings in the NBER CEX files combines a broad set of housing expenditures aside from rent paid and as a result, it is impossible to disaggregate the data at a finer level.

\footnotetext{
${ }^{33}$ See http://www.nber.org/data/ces cbo.html for the data files. See http://www.nber.org/ces cbo/Cexfam.doc for corresponding documentation.
} 
- The NBER CEX files report the sum of spending in a variety of categories across all quarters that the household participated in the survey. Households surveyed for two quarters will therefore have only half the total expenditure of otherwise identical households participating for all four quarters. The NBER CEX files do not include an indicator variable for the number of quarters that the household participated in the survey, although a summary variable indicates that less than $50 \%$ of the sample completes all fours surveys. After manually merging in the exact number of quarters that the household participated in the survey, we reexpressed the spending data on a per-quarter basis where per-quarter spending in a given category was computed as the NBER-CEX data spending in a given category divided by the number of quarters that the household participated in the survey.

We made the following restrictions to the CEX sample:

- We included only households reporting themselves as Black, White or Hispanic. We treat mixed race heads as Hispanics in our analysis. This has no effect on results, as results are the same if we exclude these households.

- We excluded households with total expenditures of over $\$ 400,000$ per year (in $\$ 2005$ ). These 98 households are the top $0.1 \%$ percent of the total expenditure distribution.

- We excluded households that changed their state of residence during the year; in which the head's education was missing (4,134 households); where the household's region was missing (617 households); and from states with fewer than 30 minorities in the CEX over the entire sample period. Excluded states were: ID, MT, NH, ND, RI, SD, VT, WV, WY. The reason for this restriction is that in the second half of the paper we compare racial consumption patterns conditional on the mean income of Blacks, Whites and Hispanics in their state residence. 


\section{Theory Appendix}

We provide the solution to a particular parametric utility specification, and a formulation of status given as own income, relative to average community group income.

We study a signaling equilibrium, similar in spirit the models of labor market signaling of Spence (1973).

Consider a situation where individuals belong to a group with mean income $\mu_{G}$. Let consumers' preferences be given by:

$$
\log \left(y^{i}-c\right)+\alpha \log (c)+s^{i}
$$

Following Duesenberry (1949), suppose that if personal income were known, status would simply be "relative income" and given by $y^{i} / \mu_{G} \cdot{ }^{34}$ However, because income is not observed, status will depend not on own income but on society's inference about income, given the person's observable consumption. Let this inference function be $g\left(c^{i}\right)$. An individual's status is thus:

$$
s^{i}=\frac{g\left(c^{i}\right)}{\mu_{G}} .
$$

A utility maximizing agent chooses consumption to satisfy the first order condition:

$$
\frac{\alpha}{c^{i}}-\frac{1}{y^{i}-c^{i}}+\frac{g^{\prime}\left(c^{i}\right)}{\mu_{G}}=0 .
$$

Since inferences about income are correct in equilibrium, $g\left(c^{i}\right)=y^{i}$ and equilibrium ${ }^{35}$ conspicuous consumption satisfies the ordinary differential equation:

$$
g^{\prime}\left(c^{i}\right)=\mu\left(\frac{1}{g\left(c^{i}\right)-c^{i}}-\frac{\alpha}{c^{i}}\right)
$$

\footnotetext{
${ }^{34}$ The relationship between status and relative income (or wealth) has long been explored in economic theory. See Cole et al (1992) and Becker et al (2005) for examples.

${ }^{35}$ Following Ireland (1994), it can be shown that given the preferences both the monotonicity and the initial value condition are satisfied. The monotonicity (single crossing condition) states that conspicuous consumption is increasing in income. The initial value condition is that the poorest individuals do not signal, i.e. their consumption of visible goods is the same as it would be without signaling.
} 
Via a change of variables $c^{i}=x^{i} y^{i}$ where $x^{i}$ is the expenditure share of conspicuous goods and redefining $w\left(x^{i}\right)=y^{i}\left(c^{i}\left(x^{i}\right)\right)=y^{i}$ we have

$$
w^{\prime}\left(x^{i}\right)=\mu_{G}\left(\frac{1}{1-x^{i}}-\frac{\alpha}{x^{i}}\right)
$$

Solving this by integration yields

$$
w^{i}(x)=\mu \int\left(\frac{1}{1-x^{i}}-\frac{\alpha}{x^{i}}\right) d x+K=-\mu_{G} \ln \left(1-x^{i}\right)-\mu_{G} \alpha \ln x^{i}+K,
$$

where the integration constant $K$ is pinned down by the initial condition:

$$
w^{-1}\left(y_{\min }\right)=x_{\min }=\frac{\alpha}{1+\alpha} .
$$

In summary, in this signaling model where status depends on relative income, the share of expenditure devoted to conspicuous consumption, or $x^{i}$, is increasing in individual income and decreasing in the mean income of the social group, $\mu_{G}$ (holding the minimum income in the community constant). 
Table 1:

Descriptive Statistics of CEX Full Sample

\begin{tabular}{lcccc}
\hline & All & White & Black & Hispanic \\
\hline Age & 35.7 & 35.8 & 35.8 & 34.5 \\
Education $<12$ & 0.11 & 0.06 & 0.14 & 0.38 \\
Education $=12$ & 0.30 & 0.28 & 0.38 & 0.29 \\
Education: Some College & 0.29 & 0.30 & 0.31 & 0.21 \\
Education: College or More & 0.30 & 0.36 & 0.16 & 0.11 \\
Married & 0.55 & 0.58 & 0.35 & 0.61 \\
Family Size & 2.9 & 2.8 & 3.0 & 3.7 \\
Number of Adults & 1.9 & 1.9 & 1.8 & 2.2 \\
Fraction with Zero Income & 0.27 & 0.26 & 0.31 & 0.25 \\
Total Family Income $\mid$ Income $>0$ & $\$ 57,858$ & $\$ 63,967$ & $\$ 38,364$ & $\$ 39,763$ \\
Total Avg. Quarterly Expenditure & $\$ 10,688$ & $\$ 11,585$ & $\$ 7,715$ & $\$ 8,420$ \\
Sample Size & 48,758 & 36,706 & 6,760 & 5,292 \\
\hline
\end{tabular}

Notes: Data from the 1986 - 2002 waves of the Consumer Expenditure Survey (CEX). All expenditures are average over all quarters that the household remained in the survey. Sample includes all individuals between the ages of 18 and 49 (inclusive) where the head reported their race as being either White, Black or Hispanic over all quarters in the sample. We also restricted the data to households that did not change their state during their sample period and who had non-missing values for their educational attainment, family size, and region. All dollar amounts are in 2005 dollars. 
Table 2: Estimated Black-White Gap in Log Visible Expenditures

With and Without Income, Expenditure, and Demographic Controls

1. No Additional Controls

2. Only Current Income Controls

3. Specification 2 Plus Expenditure Controls

4. Specification 3 Without Current Income Controls

5. Specification 3 Plus Education Controls

6. Specification 5 Plus Time Dummies

7. Specification 6 Plus Demographic and Wealth Controls
$-0.38$

(0.04)

$-0.10$

(0.03)

0.29

(0.03)

0.31

0.28

0.30

0.32

$(0.02)$
$-0.24$

(0.04)

0.01

(0.04)

0.25

(0.06)

0.26

(0.05)
0.01

Notes: See note to Table 1 for sample description and relevant sample sizes. The table reports the coefficient on the race dummies from a regression of the log of visible consumption on a race dummies and other controls. Specification 2 includes the log of current income, if income is positive, a cubic in the level of current income, and a dummy for whether current income was positive. Specification 3 also includes the log of total expenditure, and a cubic in the level of total expenditure. Specification 4 is the same as specification 3 without the income controls. Specification 5 is the same as specification 3 but also includes three education dummies (exactly high school, some college, or college or more). Specification 6 includes year dummies. Specification 7 also includes a quadratic in age, a male dummy, a married dummy, census regions dummies, a MSA dummy, an urban dummy, wealth controls, and a series of separate dummies for the number of adults and children in the household. Robust standard errors (clustered at the state level) are reported in parentheses. 
Table 3: Differences in Visible Consumption between Blacks, Whites, and Hispanics, Conditioned on Income, Expenditure and Demographic Controls

\begin{tabular}{|c|c|c|}
\hline Sample & $\begin{array}{c}\text { Black } \\
\text { Coefficient }\end{array}$ & $\begin{array}{c}\text { Hispanic } \\
\text { Coefficient }\end{array}$ \\
\hline 1. Single Men $(n=10,258)$ & $\begin{array}{c}0.32 \\
(0.03)\end{array}$ & $\begin{array}{c}0.40 \\
(0.05)\end{array}$ \\
\hline 2. Single Women $(n=13,287)$ & $\begin{array}{c}0.29 \\
(0.03)\end{array}$ & $\begin{array}{c}0.24 \\
(0.06)\end{array}$ \\
\hline 3. Married Households $(\mathrm{n}=25,213)$ & $\begin{array}{c}0.33 \\
(0.03)\end{array}$ & $\begin{array}{c}0.30 \\
(0.05)\end{array}$ \\
\hline 4. Education of Head $<12(n=5,221)$ & $\begin{array}{c}0.31 \\
(0.06)\end{array}$ & $\begin{array}{c}0.43 \\
(0.05)\end{array}$ \\
\hline 5. Education of Head $=12(n=14,425)$ & $\begin{array}{c}0.38 \\
(0.03)\end{array}$ & $\begin{array}{c}0.32 \\
(0.08)\end{array}$ \\
\hline 6. Education of Head $>12 \&<16(n=18,169)$ & $\begin{array}{c}0.30 \\
(0.03)\end{array}$ & $\begin{array}{c}0.22 \\
(0.06)\end{array}$ \\
\hline 7. Education of Head $>=16(n=17,706)$ & $\begin{array}{c}0.28 \\
(0.03)\end{array}$ & $\begin{array}{c}0.12 \\
(0.04)\end{array}$ \\
\hline 8. Age of Head Between 18 and $34(n=29,995)$ & $\begin{array}{c}0.32 \\
(0.03)\end{array}$ & $\begin{array}{c}0.32 \\
(0.06)\end{array}$ \\
\hline 9. Age of Head Between 35 and $49(n=30,544)$ & $\begin{array}{c}0.32 \\
(0.03)\end{array}$ & $\begin{array}{c}0.33 \\
(0.06)\end{array}$ \\
\hline 10. Age of Head Between 50 and $69(n=24,159)$ & $\begin{array}{c}0.22 \\
(0.04)\end{array}$ & $\begin{array}{c}0.29 \\
(0.07)\end{array}$ \\
\hline
\end{tabular}

\footnotetext{
Notes: Sample restrictions are the same as described in the note to Table 1. Additional sample restrictions are described in each row of the table. The regressions in this table have the same controls as in row 7 of Table 2. Robust standard errors (clustered at the state level) are in parenthesis.
} 
Table 4: Racial Differences in Log Spending on Specific Visible Items, Controlling for Income, Expenditure and Demographic Controls

\begin{tabular}{|c|c|c|c|c|}
\hline \multirow[b]{2}{*}{ Visible Consumption Sub-Category } & \multicolumn{2}{|c|}{ I. Full Sample } & \multicolumn{2}{|c|}{ II. Automobile Owners $(\mathrm{n}=36,986)$} \\
\hline & $\begin{array}{c}\text { Black } \\
\text { Dummy }\end{array}$ & $\begin{array}{l}\text { Hispanic } \\
\text { Dummy }\end{array}$ & $\begin{array}{c}\text { Black } \\
\text { Dummy }\end{array}$ & $\begin{array}{l}\text { Hispanic } \\
\text { Dummy }\end{array}$ \\
\hline Clothing/Jewelry & $\begin{array}{c}0.29 \\
(0.03)\end{array}$ & $\begin{array}{c}0.34 \\
(0.04)\end{array}$ & $\begin{array}{c}0.28 \\
(0.04)\end{array}$ & $\begin{array}{c}0.33 \\
(0.03)\end{array}$ \\
\hline Personal Care & $\begin{array}{c}0.56 \\
(0.05)\end{array}$ & $\begin{array}{c}0.32 \\
(0.04)\end{array}$ & $\begin{array}{c}0.59 \\
(0.05)\end{array}$ & $\begin{array}{c}0.27 \\
(0.03)\end{array}$ \\
\hline Cars (Limited) & $\begin{array}{c}0.01 \\
(0.07)\end{array}$ & $\begin{array}{c}0.12 \\
(0.13)\end{array}$ & $\begin{array}{c}0.09 \\
(0.08)\end{array}$ & $\begin{array}{c}0.16 \\
(0.13)\end{array}$ \\
\hline Cars (Including maintenance) & $\begin{array}{l}-0.33 \\
(0.10)\end{array}$ & $\begin{array}{l}-0.18 \\
(0.17)\end{array}$ & $\begin{array}{c}0.19 \\
(0.04)\end{array}$ & $\begin{array}{c}0.04 \\
(0.09)\end{array}$ \\
\hline
\end{tabular}




\section{Table 5: Differences in Log Expenditures by Category Between Blacks, Hispanics and Whites}

\begin{tabular}{|c|c|c|}
\hline Log Expenditure Category & $\begin{array}{c}\text { Black } \\
\text { Coefficient }\end{array}$ & $\begin{array}{c}\text { Hispanic } \\
\text { Coefficient }\end{array}$ \\
\hline Housing & $\begin{array}{c}0.02 \\
(0.02)\end{array}$ & $\begin{array}{c}0.04 \\
(0.03)\end{array}$ \\
\hline Utilities & $\begin{array}{c}0.12 \\
(0.03)\end{array}$ & $\begin{array}{c}-0.04 \\
(0.02)\end{array}$ \\
\hline Food & $\begin{array}{l}-0.07 \\
(0.02)\end{array}$ & $\begin{array}{c}0.03 \\
(0.02)\end{array}$ \\
\hline Other Transportation & $\begin{array}{l}-0.15 \\
(0.03)\end{array}$ & $\begin{array}{l}-0.01 \\
(0.04)\end{array}$ \\
\hline Home Furnishings ${ }^{\text {a }}$ & $\begin{array}{l}-0.21 \\
(0.03)\end{array}$ & $\begin{array}{c}0.04 \\
(0.04)\end{array}$ \\
\hline Education $^{\text {a }}$ & $\begin{array}{l}-0.17 \\
(0.09)\end{array}$ & $\begin{array}{l}-0.86 \\
(0.10)\end{array}$ \\
\hline Entertainment Services & $\begin{array}{l}-0.40 \\
(0.03)\end{array}$ & $\begin{array}{l}-0.39 \\
(0.04)\end{array}$ \\
\hline Entertainment Durables ${ }^{a}$ & $\begin{array}{l}-0.50 \\
(0.03)\end{array}$ & $\begin{array}{l}-0.23 \\
(0.04)\end{array}$ \\
\hline Health $^{\text {a }}$ & $\begin{array}{l}-0.56 \\
(0.05)\end{array}$ & $\begin{array}{l}-0.48 \\
(0.04)\end{array}$ \\
\hline Alcohol and Tobacco ${ }^{a}$ & $\begin{array}{l}-0.91 \\
(0.04)\end{array}$ & $\begin{array}{l}-1.08 \\
(0.04)\end{array}$ \\
\hline Other & $\begin{array}{c}-0.04 \\
(0.03)\end{array}$ & $\begin{array}{c}-0.38 \\
(0.03)\end{array}$ \\
\hline
\end{tabular}

\footnotetext{
a Indicates that the specification was estimated via a Tobit estimator given the non-trivial fraction of respondents who report zero spending on the category within a given year (see Table A4). Otherwise, specification was estimated via OLS.

Notes: Sample and specification for the results in this table are the same as the sample and specification shown in Row 7 of Table 2 except that the dependent variable of $\log$ visible consumption is replaced with the $\log$ of another expenditure category. Robust standard errors (clustered at the state level) are in parentheses for the OLS regressions. Bootstrapped standard errors are in parenthesis for the Tobit regressions.
} 
Table 6: Differences Among White Male-Headed Households in Log Visible Expenditures, Controlling for Own Income, Average Income of Own Race in State, Average Income of Other Races in State, Expenditure and Demographics

\begin{tabular}{|c|c|c|c|c|}
\hline & $(1)$ & $(2)$ & (3) & $(4)$ \\
\hline Log of Mean Income of White Men in State & $\begin{array}{c}-0.94 \\
(0.18)\end{array}$ & $\begin{array}{l}-0.70 \\
(0.15)\end{array}$ & $\begin{array}{c}-0.55 \\
(0.23)\end{array}$ & $\begin{array}{l}-0.78 \\
(0.15)\end{array}$ \\
\hline Log of Mean Income of All Men in State & & & $\begin{array}{l}-0.27 \\
(0.29)\end{array}$ & \\
\hline Log of Housing Expenditures & & $\begin{array}{c}-0.26 \\
(0.02)\end{array}$ & $\begin{array}{c}-0.26 \\
(0.02)\end{array}$ & $\begin{array}{l}-0.26 \\
(0.02)\end{array}$ \\
\hline Log Relative Standard Deviation of White Men & & & & $\begin{array}{c}-0.74 \\
(0.29)\end{array}$ \\
\hline $\begin{array}{l}\text { p-value difference of Log of Mean Income of White } \\
\text { Men vs. Log of Mean Income of All Men in State }\end{array}$ & & & 0.57 & \\
\hline
\end{tabular}

\footnotetext{
Notes: Sample in the table is the same as used in Tables 2 except for the additional restriction that it only includes White households ( $\mathrm{n}=36,706)$. For column (1), the specification is the same as in row 7 of Table 2 except for the following two changes: the race dummies are dropped as regressors and the log of mean total household labor income of White men in the household's state of residence is included as a regressor. In column (2), we add in log housing shelter expenditures as an additional control. In Column (3), we add both log housing shelter expenditures and log mean income of all men in the household's state of residence as an additional control. The p-value indicating whether the coefficient on log of mean White male income within the state and the coefficient on log mean income for all males within the state is shown in the fifth row of the table. In column (4), we add the log relative standard deviation of White male total household labor income to the specification in Column (2). Log relative standard deviation is computed as the log standard deviation of income for White men in a state divided by the log of mean income of White men in a state. See the text for a discussion of how we used CPS data to compute the mean income statistics by state of residence. Robust standard errors (clustered at the state level) are shown in parentheses.
} 
Table 7: Differences Among Black and Hispanic Male-Headed Households in Log Visible Expenditures, Controlling for Own Income, Average Income of Own Race in State, Average Income of Other Races in State, Expenditure and Demographics

(1) (2)

(3)

(4)

(5)

(6)

Log of Mean Income of Black Men in State

$-0.48$

Log of Mean Income of Hispanic Men in State $-0.76$

Log of Mean Own Group Income in State

$-0.56$

$-0.37$

$-0.63$

$-0.51$

$(0.13)$

(0.10)

Log Mean Income of All Men

Log of Housing Expenditures

$-0.28$

Log Relative Standard Deviation of Own Group

Income in State

p-value difference of Log of Mean Income of White

$<0.01$

Men vs. Log of Mean Income of All Men in State

Notes: This table shows the coefficients from regressions similar to those estimated in Table 6 . However, unlike Table 6 , this table includes only Black men in the sample (column $1 ; \mathrm{n}=6,760$ ), hispanic men in the sample (column $2 ; \mathrm{n}=5,292$ ), or pooled Black and hispanic men in the sample (columns $3-6$; $\mathrm{n}=$ 12,052). The log of mean household labor income of Black men or hispanic men are computed using data from the CPS and then matched to households in the CEX using state identifiers. Log of mean own group income in the state is the Black mean if the respondent is Black and is the hispanic mean if the household is hispanic. Robust standard errors (clustered at the state level) are in parentheses. 
Table 8: Racial Differences Log Visible Expenditures After Controlling for Mean Group State Income, Including Own Income, Expenditure and Demographic Controls

\begin{tabular}{|c|c|c|c|c|c|}
\hline & $(1)$ & $(2)$ & $(3)$ & $(4)$ & $(5)$ \\
\hline Black Coefficient & $\begin{array}{c}0.32 \\
(0.02)\end{array}$ & $\begin{array}{c}0.35 \\
(0.02)\end{array}$ & $\begin{array}{l}-0.09 \\
(0.08)\end{array}$ & $\begin{array}{c}0.03 \\
(0.07)\end{array}$ & $\begin{array}{c}0.02 \\
(0.08)\end{array}$ \\
\hline Hispanic Coefficient & $\begin{array}{c}0.31 \\
(0.05)\end{array}$ & $\begin{array}{c}0.34 \\
(0.04)\end{array}$ & $\begin{array}{l}-0.07 \\
(0.09)\end{array}$ & $\begin{array}{c}0.04 \\
(0.07)\end{array}$ & $\begin{array}{c}0.02 \\
(0.08)\end{array}$ \\
\hline Log of Mean Own Group Income in State & & & & $\begin{array}{l}-0.52 \\
(0.14)\end{array}$ & $\begin{array}{l}-0.52 \\
(0.14)\end{array}$ \\
\hline $\begin{array}{l}\text { Log of Relative Standard Deviation of Own } \\
\text { Group Income in State }\end{array}$ & & & & & $\begin{array}{c}0.23 \\
(0.14)\end{array}$ \\
\hline \multicolumn{6}{|l|}{ Adjusted R-Squared } \\
\hline State Fixed Effects Included & No & Yes & No & Yes & Yes \\
\hline
\end{tabular}


Table 9: Racial Differences in Education, Health Care, Food Expenditures, and Housing Expenditures, With and Without Controls for Visible Spending

\begin{tabular}{lcc}
\hline \hline Controls & $\begin{array}{c}\text { Black } \\
\text { Coefficient }\end{array}$ & $\begin{array}{c}\text { Hispanic } \\
\text { Coefficient }\end{array}$ \\
\hline \multicolumn{4}{c}{ Panel A: Dependent Variable is Log Education Spending } \\
\hline 1. Baseline & -0.17 & -0.85 \\
& $(0.09)$ & $(0.10)$ \\
2. Baseline plus Housing Share of Total Expenditures & -0.20 & -0.81 \\
& $(0.08)$ & $(0.10)$ \\
3. Baseline plus Housing Share of Total Expenditures and & 0.05 & -0.57 \\
Visible Expenditure Share of Total Expenditures & $(0.08)$ & $(0.10)$ \\
\end{tabular}

Panel B: Dependent Variable is Log Health Care Spending

1. Baseline

$-0.56$

$-0.48$

$(0.03)$

$(0.04)$

2. Baseline plus Housing Share of Total Expenditures

$-0.56$

$-0.46$

$(0.03)$

$(0.04)$

3. Baseline plus Housing Share of Total Expenditures and

$-0.48$

$-0.37$

Visible Expenditure Share of Total Expenditures

$(0.03)$

$(0.04)$

\section{Panel C: Dependent Variable is Log Food Spending}

1. Baseline

$-0.07$

(0.02)

0.03

$-0.07$

2. Baseline plus Housing Share of Total Expenditures

$-0.07$

0.04

(0.02)

3. Baseline plus Housing Share of Total Expenditures and

$-0.03$

0.07

Visible Expenditure Share of Total Expenditures

$(0.02)$

$(0.02)$

Panel D: Dependent Variable is Log Housing Spending

1. Baseline

0.02

0.04

$(0.03)$

$(0.03)$

2. Baseline plus Visible Expenditure Share of

0.08

0.09 Total Expenditures

(0.02)

$(0.02)$

Notes: Row 1 of this table estimates racial differences in spending on education (panel A), health care (panel B), food (panel C) and housing (panel D) analogous to the regressions shown in Table 5. See notes to Table 5 for details. In row 2 of Panels A-C, we add the share of expenditures allocated to housing as an additional control. In the last row of each panel, we added the share of expenditure allocated to visible goods as an additional control. 


\section{Table 10: Racial Differences Wealth Levels After Controlling for Mean Group State Income, Including Own Permanent Income and Demographic Controls}

Controls In Addition to the Black Dummy

1. Only a Black Dummy

2. Permanent Income and Demographic Controls

3. Permanent Income and Demographic Controls, Plus State Fixed Effects

4. Permanent Income and Demographic Controls, Plus Log of Mean Own Group Income in State

Dependent Variable

Sample Size
Coefficient on Black Dummy

$-97,046$

$-40,138$

$-15,862$

$(15,365)$

Total Net Worth Less Vehicle Net Worth

2,019

Notes: Data come from the 1994 - 1999 Waves of the Panel Study of Income Dynamics (PSID). Table reports the coefficient on a Black dummy from a regression of total net worth less vehicle wealth in 1999 on a Black dummy and a series of additional controls. In Row 1 , the only control in the regression is the Black dummy. In Row 2, we also include permanent income and demographic controls. Our permanent income measure is total family labor income averaged over all years the household was in the sample between 1994 and 1999. We include a quartic in permanent income in the regression. Our demographic controls include a quadratic in age, education dummies, family size dummies, dummies for the number of children in the household, marital status dummies, and a male dummy. The log of mean own group income in the state is the same as defined in the previous tables. The sample is restricted to all Black and White households in the 1999 PSID between the ages of 18 and 49 (inclusive). The top/bottom five percent of the wealth distribution is truncated. 
Appendix Table A1: Aggregation of the NBER CEX Files Analyzed in this Paper

\begin{tabular}{|c|c|}
\hline Our Spending Categories & Corresponding NBER CEX Spending Categories \\
\hline \multicolumn{2}{|c|}{ Visible Spending Components } \\
\hline Clothing/Jewelry & $\begin{array}{l}\text { Clothing and Shoes (029), Clothing Services (030), Jewelry } \\
\text { and Watches (031) }\end{array}$ \\
\hline Personal Care & $\begin{array}{l}\text { Toilet Articles and Preparations (032), Barbershops, Beauty } \\
\text { Parlors, and Health Clubs (033) }\end{array}$ \\
\hline Vehicle (Limited) & Net Outlay on New and Used Motor Vehicles (052) \\
\hline Vehicle (Expanded) & $\begin{array}{l}\text { Net Outlay on New and Used Motor Vehicles (052), Repair, } \\
\text { Leasing, Greasing, Washing, Parking, Storage, and Rental } \\
\text { (054), Reduction of Principal on Vehicle Loan (096), Tires, } \\
\text { Tubes, Accessories, and Other Parts (053) }\end{array}$ \\
\hline
\end{tabular}

Other Spending Components

Housing

Food

Utilities

Other Transportation

Entertainment Services

Entertainment Durables

Alcohol and Tobacco

Household Furnishings

Education

Tenant-Occupied Nonfarm Dwellings - Rent (including the rental of furniture and appliances) (034), Rental Equivalence of Owned Home (075)

Food Off-Premise (023), Food On-Premise (024), Food Furnished Employees (025)

Electricity (038), Gas (039), Water and Other Sanitary Services (040), Fuel Oil and Coal (040), Telephone (042)

Vehicle Gasoline and Oil (055), Bridge, Tunnel, Ferry, and Toll Roads (056), Auto Insurance (057), Mass Transit Systems (058), Taxicab, Railway, Bus, and Other Travel (059)

Recreation Services (060), Books and Maps (061), Magazines, Newspapers, Nondurable Toys (062)

Recreation and Sports Equipment (063)

Tobacco Products (026), Alcohol Off-Premise (027), Alcohol On-Premise (028)

Furniture and Durable Household Equipment (036)

Higher Education (066), Nursery, Elementary and Secondary Education (067), Other Education Services (068)

Health

Prescription Drugs (044), Opthalmic Products and Orthopedic Appliances (045), Physicians, Dentists, Other Medical Professionals (046), Hospitals (047), Nursing Homes (048), Health Insurance (049)

Other

Nondurable Household Supplies and Equipment (037), Domestic Service, Other Household Operation (043), Business Services (050), Expense of Handling Life Insurance (051), Pari-Mutuel Net Receipts (065), Religious and Welfare Activities (069)

A full description of the NBER CEX categories can be found at: http://www.nber.org/ces_cbo/Cexfam.doc 


\section{Appendix Table A2: Survey Questions}

\section{Q1: Background Information}

Sex (male or female) ; Age ; Race (White, Black, Hispanic, Asian, Native American, or other) ; Current Marital Status (single; married)

\section{Q2: Beliefs About the Visibility of Consumption Categories}

In this set of questions, we are attempting to gauge how easy it is to observe the amount someone spends on a broad set of consumption categories.

Consider a person who lives in a household and community roughly similar to yours. How closely would you have to interact with this person in order to observe that they consistently spend more than average on each of the following consumption categories?

Your answers should range from 1 to 5 with:

$1=\quad$ I would observe their above average spending even if I did not interact with them socially at all.

$2=\quad$ I would observe their above average spending if they were a casual acquaintance and I only occasionally interacted with them socially.

$3=\quad$ I would observe their above average spending only if they were a friend.

$4=\quad$ I would observe their above average spending only if they were a close friend.

$5=\quad$ I would never observe their above average spending no matter how much I interacted with them socially.

\section{Q3: Response of Spending to Income Changes}

In this set of questions, we are trying to understand one's perceptions about the relationship between income and consumption for a variety of consumption categories.

Consider a randomly chosen individual in society. Imagine that this person's lifetime income suddenly increased by $20 \%$. For each item below, tell us how you would expect the person's spending on each of the following items to change.

$1=\quad$ Spending would fall

$2=\quad$ Spending would stay the same

$3=\quad$ Spending would increase by less than $20 \%$

$4=\quad$ Spending would increase by exactly $20 \%$

$5=\quad$ Spending would increase by more than $20 \%$

Categories respondents asked about (exact wording): Grocery Expenditures (food purchased at grocery stores excluding spending on tobacco products and alcohol); Non Grocery Food Expenditures (restaurants, cafeterias, etc.); Alcohol; Tobacco Products (cigarettes, cigars, etc.); Clothing, Shoes, and Clothing Accessories; Jewelry and Watches; Personal Care and Grooming Expenditures (including hair care, makeup, perfume, and gym memberships); Shelter Expenditures (monthly rent payment, house value, etc.), Household Utilities (expenditures for telephone service, home heating, home electricity, etc.); Value of Owned and Leased Vehicles (excluding expenditures on maintenance and repair); Vehicle Maintenance and Repair (oil changes, car repairs, other car maintenance); Other Transportation Expenses (gasoline, public transportation, parking fees, rental cars, etc.); Home Furnishings (furniture, linens, dishes, etc.); Entertainment Durables (television sets, stereos, sports equipment, other entertainment equipment); Other Entertainment Expenditures (DVDs, cads, movie tickets, golf fees, books, periodicals, cable television fees, vacation travel); Children's Education (tuition, books, other school related expenses); Health Expenses (health insurance, out of pocket medical expenses, prescription drugs); and Charitable Giving (including religious giving). 


\section{Appendix Table A3: Results of the Visible Goods Survey}

\begin{tabular}{|c|c|c|}
\hline Category & $\begin{array}{l}\text { Fraction of the Sample } \\
\text { Reporting Consumption Item } \\
\text { as Easily Observable }\end{array}$ & $\begin{array}{c}\text { Fraction of the Sample } \\
\text { Reporting Consumption Item } \\
\text { as Having Income Elasticity of } \\
1 \text { or More }\end{array}$ \\
\hline Clothing & 0.64 & 0.57 \\
\hline Jewelry & 0.62 & 0.52 \\
\hline Vehicles (Non Maintenance) & 0.49 & 0.44 \\
\hline Personal Care & 0.31 & 0.35 \\
\hline Tobacco & 0.40 & 0.16 \\
\hline Alcohol & 0.35 & 0.07 \\
\hline Shelter & 0.37 & 0.47 \\
\hline Food Away From Home & 0.24 & 0.47 \\
\hline Entertainment Durables & 0.17 & 0.53 \\
\hline Other Entertainment & 0.12 & 0.50 \\
\hline Children's Education & 0.15 & 0.30 \\
\hline Groceries & 0.08 & 0.05 \\
\hline Utilities & 0.06 & 0.05 \\
\hline Home Furnishings & 0.09 & 0.37 \\
\hline Other Transportation & 0.05 & 0.08 \\
\hline Charity & 0.04 & 0.18 \\
\hline Health & 0.02 & 0.07 \\
\hline Vehicle Maintenance & 0.03 & 0.07 \\
\hline \multicolumn{3}{|c|}{$\begin{array}{l}\text { Notes: This table summarizes the results of our survey of } 213 \text { graduate students about their beliefs about } \\
\text { what goods are visible. Appendix Table A2 outlines the exact wording of the survey questions. Column } 1 \\
\text { reports the fraction of households who answered } 1 \text { or } 2 \text { to survey question Q2. Answers } 1 \text { or } 2 \text { indicated } \\
\text { that the survey respondents would be able to ascertain above average spending on the consumption } \\
\text { category for individuals with which the respondent was relatively unfamiliar. Column } 2 \text { reports the } \\
\text { fraction of households who answered } 4 \text { or } 5 \text { to survey question Q3. Answers of } 4 \text { and } 5 \text { indicate that the } \\
\text { survey respondent believed there was a unitary income elasticity or greater with respect to spending on the } \\
\text { consumption category. }\end{array}$} \\
\hline
\end{tabular}


Appendix Table A4:

Mean Quarterly Expenditure (in 2005 dollars), Percent with Positive Expenditures, and Expenditure Shares by Consumption Category, by Race

\begin{tabular}{|c|c|c|c|c|}
\hline & All & White & Black & Hispanic \\
\hline \multirow[t]{3}{*}{ Visible Expenditures } & 1,671 & 1,801 & 1,256 & 1,317 \\
\hline & 0.99 & 0.99 & 0.99 & 0.99 \\
\hline & 0.12 & 0.12 & 0.12 & 0.12 \\
\hline \multirow[t]{3}{*}{ Shelter Expenditures } & 2,492 & 2,670 & 1,826 & 2,145 \\
\hline & 0.99 & 0.98 & 0.99 & 0.99 \\
\hline & 0.25 & 0.25 & 0.26 & 0.28 \\
\hline \multirow[t]{3}{*}{ Food Expenditures } & 1,659 & 1,733 & 1,294 & 1,630 \\
\hline & 1.00 & 1.00 & 1.00 & 1.00 \\
\hline & 0.18 & 0.17 & 0.21 & 0.22 \\
\hline \multirow[t]{3}{*}{ Utility Expenditures } & 742 & 757 & 732 & 646 \\
\hline & 0.99 & 0.99 & 0.99 & 0.99 \\
\hline & 0.08 & 0.07 & 0.11 & 0.09 \\
\hline \multirow[t]{3}{*}{ Vehicle Service Expenditures } & 796 & 874 & 576 & 542 \\
\hline & 0.88 & 0.93 & 0.71 & 0.80 \\
\hline & 0.07 & 0.07 & 0.06 & 0.05 \\
\hline \multirow[t]{3}{*}{ Other Transportation Expenditures } & 669 & 715 & 498 & 575 \\
\hline & 0.98 & 0.99 & 0.96 & 0.97 \\
\hline & 0.07 & 0.07 & 0.06 & 0.07 \\
\hline \multirow[t]{3}{*}{ Entertainment Service Expenditures } & 576 & 665 & 291 & 331 \\
\hline & 0.98 & 0.99 & 0.95 & 0.95 \\
\hline & 0.05 & 0.07 & 0.04 & 0.04 \\
\hline \multirow[t]{3}{*}{ Health Expenditures } & 412 & 464 & 245 & 274 \\
\hline & 0.85 & 0.89 & 0.74 & 0.76 \\
\hline & 0.04 & 0.04 & 0.03 & 0.03 \\
\hline
\end{tabular}

\footnotetext{
Notes: See notes to Table 1 for full sample description. See Appendix Table A1 for the definition of each consumption categories. For each consumption category, the first row shows the average spending per quarter in that category (in 2005 dollars), the second row shows the fraction of households with positive spending in the consumption category, and the third row shows the share of expenditures in the consumption category out of total expenditures. Columns 1-4, respectively, show the relevant statistics for the total population, a sample with White heads, a sample with Black heads, and a sample of Hispanic heads.
} 
Appendix Table A4 (continued):

Mean Expenditure (in 2005 dollars), Percent with Positive Expenditures, and Expenditure Shares by Consumption Category, by Race

\begin{tabular}{lcccc}
\hline \hline & All & White & Black & Hispanic \\
\hline Home Furnishing Expenditures & 311 & 348 & 186 & 221 \\
& 0.83 & 0.86 & 0.71 & 0.79 \\
& 0.03 & 0.03 & 0.02 & 0.02 \\
Education Expenditures & & & & \\
& 253 & 288 & 170 & 121 \\
& 0.43 & 0.46 & 0.34 & 0.30 \\
Entertainment Durable Expenditures & 0.02 & 0.02 & 0.02 & 0.01 \\
& 248 & 290 & 110 & 140 \\
Alcohol/Tobacco Expenditures & 0.80 & 0.85 & 0.64 & 0.72 \\
& 0.02 & 0.02 & 0.01 & 0.02 \\
& & & & 124 \\
Other Expenditures & 213 & 243 & 123 & 0.70 \\
& 0.82 & 0.86 & 0.68 & 0.02 \\
& 0.02 & 0.03 & 0.02 & 354 \\
& & & & 0.85 \\
& 647 & 736 & 403 & 0.03 \\
& 0.92 & 0.94 & 0.86 & 5,292
\end{tabular}


Table A5: Alternate Estimates of the Differences in Visible Consumption Between Blacks, Hispanics, and Whites, Conditioned on Income and Demographic Controls

\begin{tabular}{|c|c|c|}
\hline Specification & $\begin{array}{c}\text { Black } \\
\text { Coefficient }\end{array}$ & $\begin{array}{c}\text { Hispanic } \\
\text { Coefficient }\end{array}$ \\
\hline 1. Restrict Current Household Income $>0(n=30,306)$ & $\begin{array}{c}0.32 \\
(0.03)\end{array}$ & $\begin{array}{c}0.30 \\
(0.05)\end{array}$ \\
\hline 2. $\quad$ Restrict Total Expenditure $>\$ 5,800 /$ quarter $(\mathrm{n}=34,750)$ & $\begin{array}{c}0.35 \\
(0.02)\end{array}$ & $\begin{array}{c}0.24 \\
(0.06)\end{array}$ \\
\hline 3. Restrict Age to be between 24 and 49 (inclusive) $(n=43,278)$ & $\begin{array}{c}0.34 \\
(0.02)\end{array}$ & $\begin{array}{c}0.32 \\
(0.05)\end{array}$ \\
\hline 4. Restrict Sample to Only Those With 4 completed CEX surveys $(n=26,932)$ & $\begin{array}{c}0.34 \\
(0.02)\end{array}$ & $\begin{array}{c}0.30 \\
(0.05)\end{array}$ \\
\hline 5. Include Log Housing Expenditure Control $(n=48,758)$ & $\begin{array}{c}0.33 \\
(0.02)\end{array}$ & $\begin{array}{c}0.32 \\
(0.05)\end{array}$ \\
\hline 6. Include Occupation Dummies $(\mathrm{n}=34,782)$ & $\begin{array}{c}0.32 \\
(0.03)\end{array}$ & $\begin{array}{c}0.29 \\
(0.05)\end{array}$ \\
\hline 7. Restrict Years $1996-2003(n=23,875)$ & $\begin{array}{c}0.35 \\
(0.04)\end{array}$ & $\begin{array}{c}0.33 \\
(0.05)\end{array}$ \\
\hline 8. Restrict Years 1996 - 2003: With City Size Controls $(n=23,875)$ & $\begin{array}{c}0.40 \\
(0.04)\end{array}$ & $\begin{array}{c}0.38 \\
(0.04)\end{array}$ \\
\hline
\end{tabular}


Figure 1:

Visible Good Engel Curves Separately for Blacks and Whites

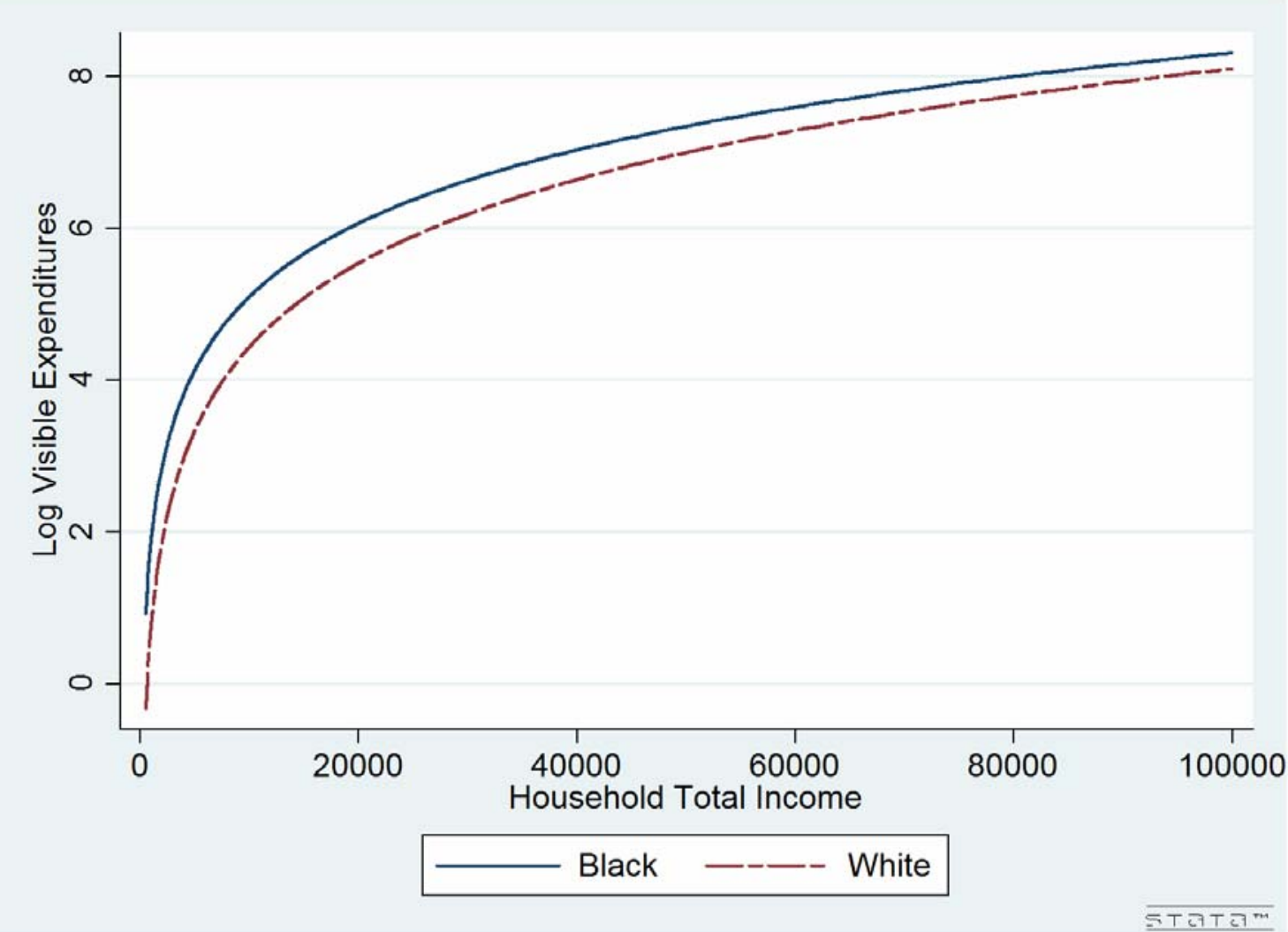

Notes: Figure shows the Engle Curve estimates of log visible expenditures on log family income separately for Blacks (solid line) and Whites (dotted line) using expenditure and income data from the CEX. CEX family income was instrumented using log total expenditures and a cubic in the level of total expenditures. The respective Black and White samples only included those households who reported positive family income. The regressions were estimated over a similar range populated by both Black and White households. Specifically, the regression was only estimated for households with annual total family income less than $\$ 100,000$ (in 2005 dollars). This income cutoff was approximately the $99^{\text {th }}$ percentile of the Black income distribution. The estimated coefficient from the White Engle curve and the Black Engel curve, respectively, were 1.59 (standard error $=0.02)$ and $1.40($ standard error $=0.04)$. The corresponding intercepts, respectively, were $-10.20($ standard error $=0.24)$ and $-7.76($ standard error $=0.39)$. 


\section{Figure 2a: Visible Expenditures}

State Fixed Effect $=0.56-0.017$ Mean State Income $(\$ 1000)$ t-stat for Mean State Income $=-4.60$ and Adjusted R-squared $=0.353$

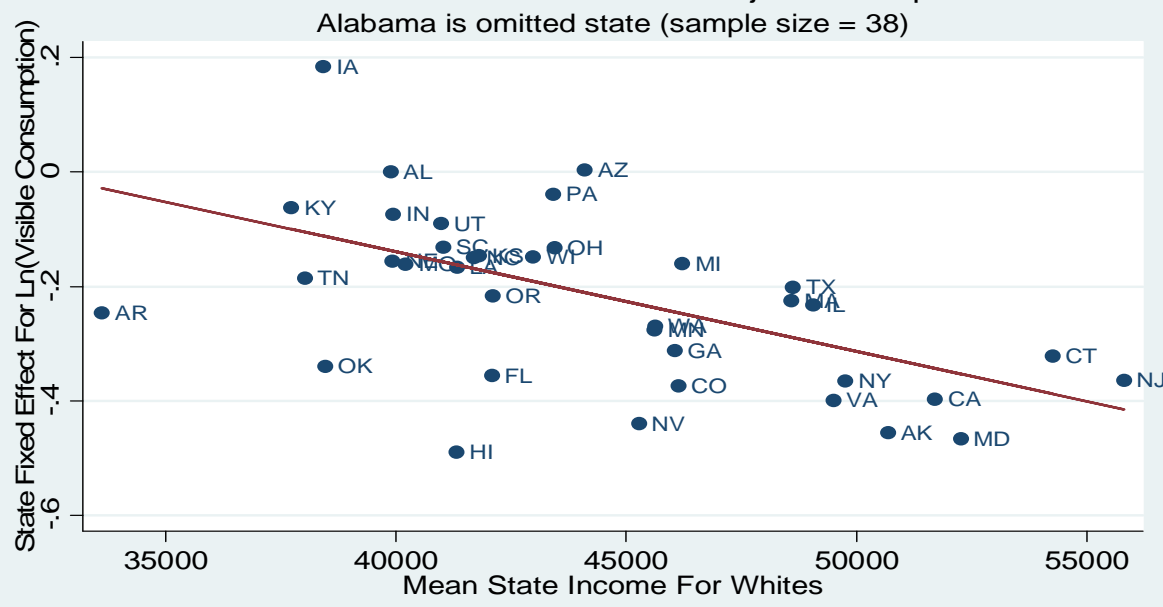

Figure 2b: Housing Expenditures

State Fixed Effect $=-0.80+0.022$ Mean State Income $(\$ 1000)$ t-stat for Mean State Income $=5.28$ and Adjusted R-squared $=0.421$

Alabama is omitted state (sample size $=38$ )

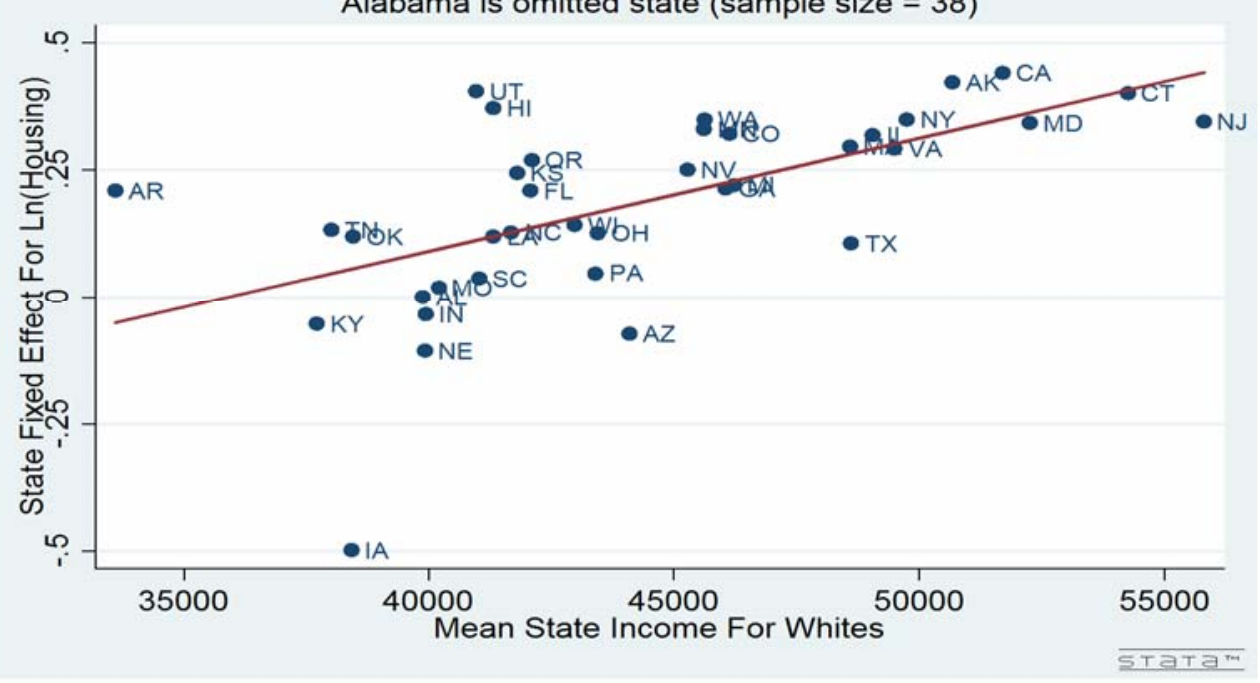




\section{Figure 2c: Visible Expenditure Controlling for Housing Expenditures}

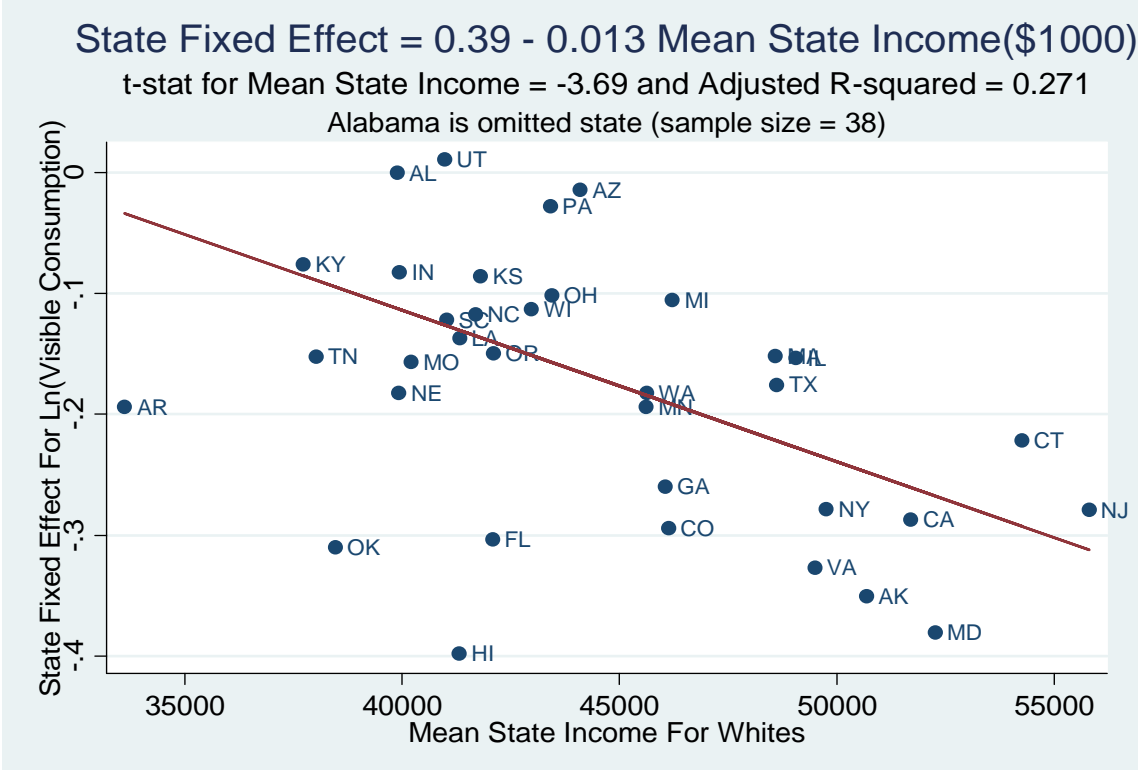

Figure 2d: Food Expenditures Adjusted For Housing Expenditures

State Fixed Effect $=-0.30+0.006$ Mean State Income $(\$ 1000)$

t-stat for Mean State Income $=3.32$ and Adjusted R-squared $=0.213$

Alabama is omitted state (sample size $=38$ )

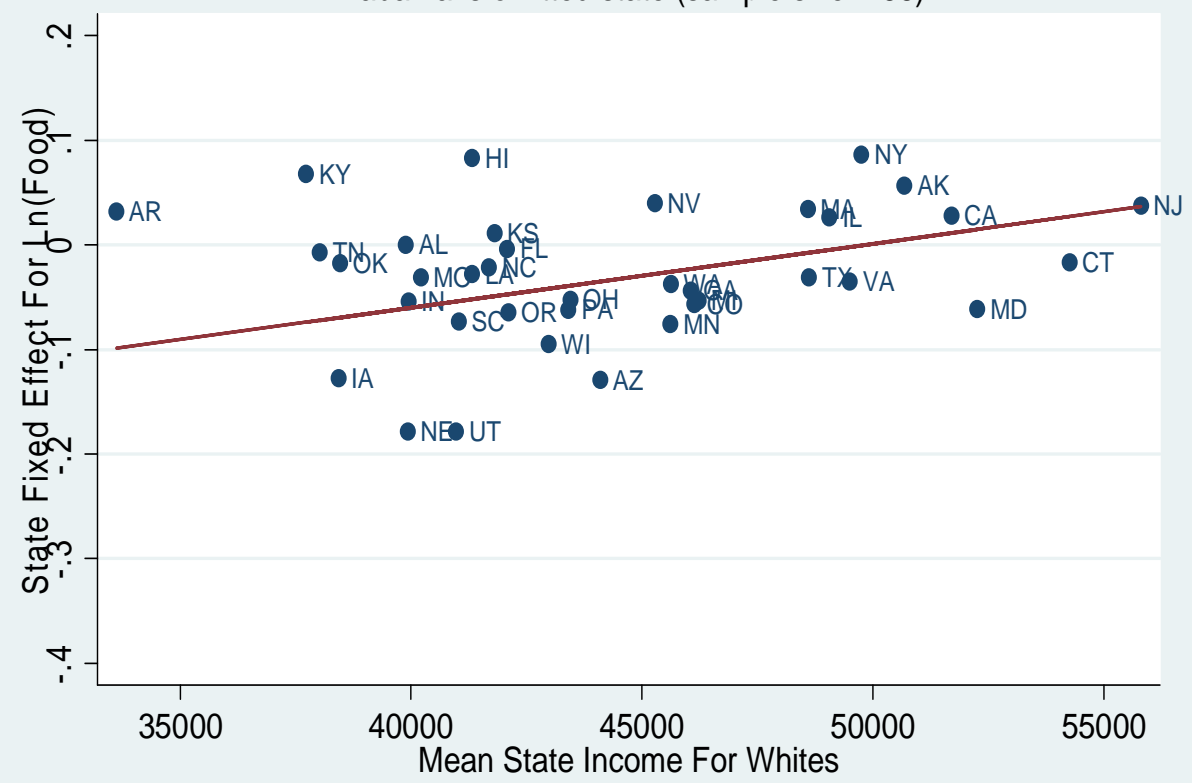


Figure 2e: Entertainment Expenditures Adjusted For Housing Expenditures

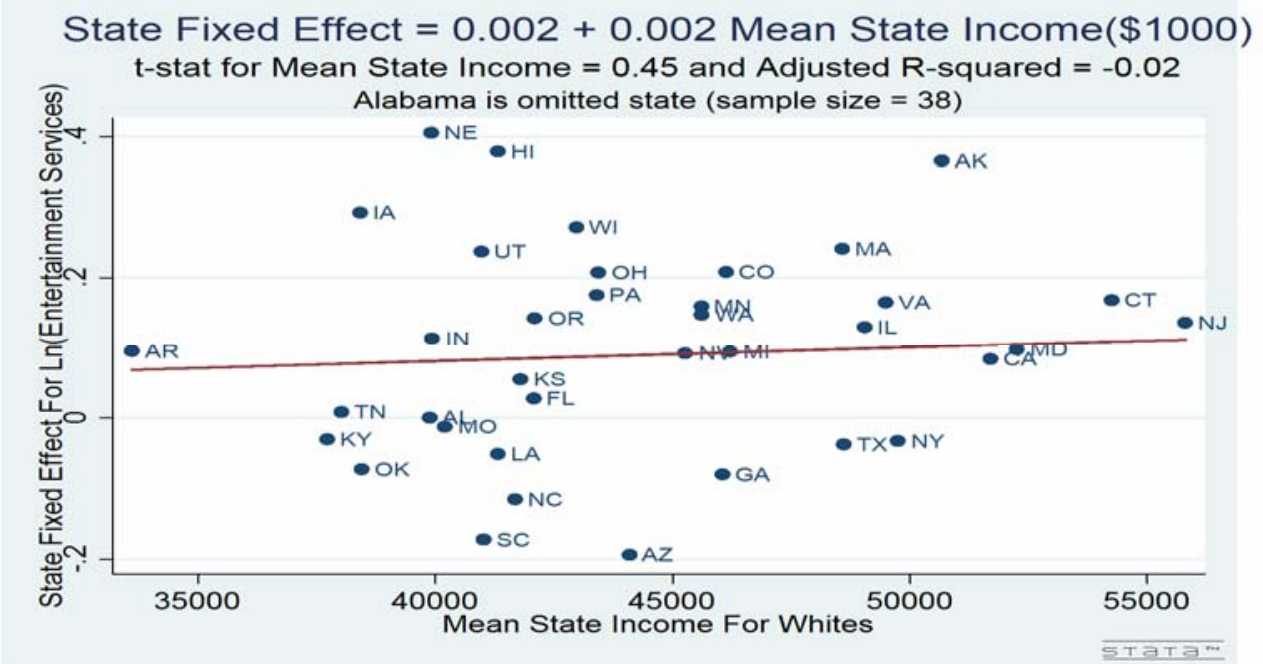

\section{Figure 2f: All Non-Visible, Non-Housing Expenditures Adjusted For Housing Expenditures}

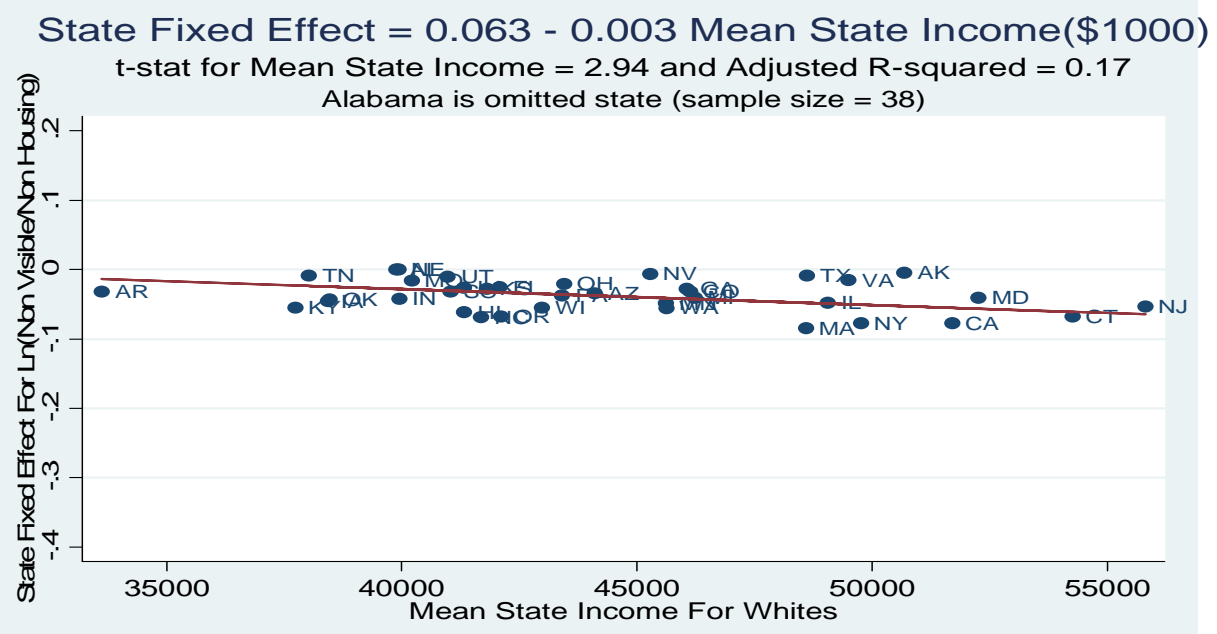

Note: This figure plots the coefficients on state fixed effect from a regression of log total expenditure in a given expenditure category on state fixed effects and income, expenditure, demographic controls, and log housing shelter expenditures for White households against mean total family labor income of White males in the corresponding state. The sample and controls used in the regression to estimate the state fixed effects are otherwise identical to the one used in Row 7 of Table 2. Alabama was the omitted state fixed effect. All state fixed effect coefficients (vertical axis) are percentage differences from an otherwise identical household from Alabama. A regression line is fitted through the data weighting each point by the number of observations from each state from the regression sample. Only 38 states were included in the regression due to the fact that some states are not sample in the CEX. See text for a complete discussion. The only differences between figures $2 \mathrm{a}-2 \mathrm{f}$ are 1) the dependent variable in the regression to get the state fixed effects and 2) whether or not log housing expenditures were included as a control. The title to the figures identifies the dependent variable and whether or not housing expenditures were included as a control. 